\title{
La cooperación sur-sur de Brasil y Colombia: entre la política exteriory el desarrollo
}

\section{South-South Cooperation of Brazil and Colombia: Between Foreign Policy and Development}

\author{
Paula Ximena Ruiz Camacho* \\ Universidad Externado de Colombia \\ ORCID: https://orcid.org/oooo-00o2-6848-9936
}

Fecha de recepción: 31, octubre, 2017

Fecha de publicación: 18, diciembre, 2017

\section{Resumen}

La cooperación Sur-Sur (CSS) es una modalidad complementaria a la tradicional cooperación Norte-Sur, la cual se ha fortalecido a lo largo de este siglo como un instrumento de soft power ejecutado por los países del Sur global. Suramérica ha sido la región más activa en cuanto a su formulación y ejecución, o bien para obtener un mayor grado de autonomía política y económica en la definición de sus proyectos de desarrollo, o bien para mejorar su posicionamiento y visibilidad dentro del sistema internacional de cooperación al desarrollo. Tal es el caso de la implementación de las estrategias adoptadas por Brasil y Colombia en materia de cooperación, la cual será inicialmente definida como la manifestación de los intereses nacionales a través del diseño y la puesta en marcha de su política exterior. Por lo anterior, el objetivo de este artículo es analizar la CSS, tanto de Brasil como de Colombia, como herramienta de política exterior a través de dos factores: la identidad y la expertise institucional.

\section{Abstract}

South-South cooperation is a complementary modality to the traditional North-South Cooperation, which has been strengthened throughout this century as a soft power instrument executed by the countries of the global South. South America has been the most active region to obtain a greater degree of political and economic autonomy in the definition of its development projects, and also to improve its positioning and visibility within the international development cooperation system. Such is the case of the strategies adopted by Brazil and Colombia in terms of cooperation, which will be initially defined as the appearance of their national interests through the design and implementation of their foreign policy. Therefore, the objective of this article is to analyze the SSC of Brazil and Colombia as a foreign policy tool through two factors: identity and institutional expertise.

doi:10.11144/Javeriana.papo23-1.ccep

*Autor de correspondencia: paula.ruiz@uexternado.edu.co 


\section{Palabras clave}

cooperación Sur-Sur; política exterior; Brasi

Colombia

\section{Cómo citar este artículo:}

Ruiz-Camacho, P. X. (2018). La cooperación

Sur-Sur de Brasil y Colombia: entre la política

exterior y el desarrollo. Papel Político, 23(1),

209-248. https://doi.org/10.11144/Javeriana.

papo23-1.ccep

\section{Keywords}

South-South cooperation; foreign policy; Brazil; Colombia 


\section{Introducción}

A lo largo de este siglo, una de las preocupaciones centrales en materia de cooperación internacioal al desarrollo (CID) ha girado alrededor de cómo hacerla más eficaz, pregunta que ha buscado resolverse a través de la definición de instrumentos y mecanismos conjuntos que lleven a sus principales agentes, los Estados, a repensar el sistema de cooperación internacional al desarrollo. ${ }^{2}$

Distintos encuentros internacionales que se han desarrollado desde 2000, cuando fueron aprobados los Objetivos de Desarrollo del Milenio (ODM) hasta hoy, dan cuenta de ello. En esta línea, los países del llamado Sur global buscan dinamizar su rol en materia de CID fortaleciendo la cooperación Sur-Sur (CSS) como un instrumento de la agenda de política exterior de los países en desarrollo.

Por tanto, parte de la respuesta surge del fortalecimiento de alianzas en las que se destacan liderazgos regionales como los de Brasil, la India y Sudáfrica, países que buscan mejorar su posicionamiento en el escenario internacional a través de coaliciones SurSur (John de Sousa, 2007; Gratius, 2007; Lechini, 2007), desde las cuales "promover una distribución de poder más justa y equitativa” (Gratius, 2007, p. 5), alianzas que se materializan a través de acuerdos de integración comercial y de mayor cooperación al desarrollo entre ellos, para fortalecer una especie de "multilateralismo del sur" y un lugar privilegiado en sus regiones. Un ejemplo de relaciones interregionales desarrolladas por estos tres países es la consolidación del India-Brazil-South Africa Dialogue Forum (IBSA). ${ }^{3}$

XXAdemás, con estas transformaciones, también se fortalecen en las regiones otros países o potencias secundarias (Flemes, 2012a; Pastrana, 2012), definición que será abordada más adelante y desde cuya posición se analiza el caso de Colombia, cuyo principal objetivo es obtener mayor visibilidad en el sistema y, por supuesto, un mayor grado de autonomía para la toma de decisiones en materia de sus políticas económicas y sociales ${ }^{4}$ e, incluso, mayor injerencia en las negociaciones relacionadas con temas alrededor del desarrollo en el marco de las organizaciones internacionales.

Tanto el auge como el dinamismo de la CSS de los últimos años hace parte de algunos de esos cambios sufridos en el orden internacional pos-Guerra Fría. Dentro del sistema internacional de cooperación al desarrollo, se reconoce cada vez más la participación de aquellos agentes que eran considerados pasivos dentro del proceso, es decir, los países receptores o países en desarrollo (Vidal, Guillén y Déniz, 2010), que promueven las principales propuestas de cambio a las estructuras del sistema internacional de cooperación al desarrollo para hacer de esta un instrumento más eficaz; cuenta de ello dan los diversos informes que, por ejemplo, desde la Secretaría General Iberoamericana (Segib) se producen sobre el tema. ${ }^{5}$

La eficacia de la cooperación al desarrollo ha sido foco de intensos debates alrededor de sus verdaderos objetivos y de la manera como esta se ejecuta. Como resultado de ello, 
desde diversos escenarios, se ha propuesto un rediseño de las políticas globales en materia social y económica para que sean transversales a un desarrollo con un enfoque sostenible. ${ }^{6}$

Asimismo, agentes no estatales como las organizaciones no gubernamentales (ONG), las organizaciones de la sociedad civil (OSC) e incluso el sector privado, que actúan de manera más decidida en la formulación y gestión de proyectos de cooperación, se vinculan al debate. Los distintos agentes desempeñan papeles diferenciados dentro del proceso de redefinición del sistema de cooperación al desarrollo, bien sea de manera más directa a través de diversas negociaciones y encuentros internacionales, como es el caso de los Estados (tanto donantes como receptores), las organizaciones internacionales y las ONG, bien sea de manera indirecta, aquellos actores que la estudian, observan y evalúan desde posturas más críticas, como el sector académico, think tanks o el sector privado, así como un amplio universo de las OSC (Marín, 2017).

Este tipo de iniciativas lo que busca es fortalecer los mecanismos de gestión a través de la definición de una agenda global para el desarrollo (Sachs, 2014), en la cual, tal como lo define la nueva Agenda 2030 bajo la cual se aprueban los Objetivos de Desarrollo Sostenible (ODS), se priorice "el principio de no dejar a nadie atrás, es decir, el valor de la equidad, que el desarrollo llegue a todos los países, grupos y personas" (Surasky, 2017, p. 82); en otras palabras, que sea inclusiva para todos los actores que componen el sistema internacional de cooperación al desarrollo.

En términos generales, se resalta la urgencia de adaptar la CID a los cambios del sistema internacional, a las necesidades y capacidades reales de los países, ajustando las reglas y los acuerdos que faciliten el intercambio y le den mayor transparencia a la información, que se establezcan unos lineamientos comunes, tal como buscó hacerse en la Declaración de París sobre Eficacia de la Ayuda de 2005, en la que se acordaron cinco principios: apropiación, alineación, armonización, gestión orientada a resultados y la mutua responsabilidad (Organisation for Economic Co-operation and Development [OECD], 2005/2008).

Los debates sobre la eficacia de la ayuda también han estado centrados en fortalecer distintas modalidades de CID, como la ya mencionada CSS, la cooperación triangular, ${ }^{7}$ o la cooperación privada, entre otras. Pero, asimismo, se resalta la necesidad de reforzar los mecanismos de financiación en los que, por ejemplo, los países del sur a través de sus capacidades e instituciones locales puedan "movilizar recursos internos (ahorro interno, mercados de crédito y de capital) con mejoras en los mecanismos para acceder a recursos externos, tanto privados como oficiales" (Sagasti y Prada, 2010, p. 8), de ahí la relevancia que han tomado los nuevos donantes emergentes como agentes alternos, capaces de ejecutar recursos y movilizar conocimientos a un amplio y variado grupo de países del sur, tal es el caso de Brasil durante gran parte de las últimas dos décadas.

Para la mayoría de los países del sur, estos procesos de integración y de cooperación se presentan como alternativas, "que más allá de lo económico, buscan resistirse 
políticamente a continuar con las hegemonías imperantes del sistema mundial” (Altinbaş, 2013, p. 31), que en cuanto a la CID es el rechazo a la imposición de agendas diseñadas desde el norte para el sur, que en parte fue lo que sucedió con los ODM. Los intereses movilizados por los países del sur, han impulsado la formulación de agendas para el desarrollo más incluyentes y universales, ambas características de la Agenda 2030 que contiene los 17 ODS.

En cuanto a Suramérica, es una región que paulatinamente ha venido ampliando su campo de acción en materia de CSS, la gran mayoría de los Estados la han vinculado como parte integral de su estrategia en materia de política exterior. Sin embargo, a pesar de existir un consenso general sobre cuáles son los principios que la rigen, cada país la define, desarrolla y evalúa de maneras distintas, lo que dificulta hacer un análisis generalizado sobre el verdadero liderazgo de la región en la ejecución de la CSS y, más aún, sobre su impacto en el desarrollo de sus países.

Estudiar los casos de Brasil y Colombia permite evidenciar estas diferencias, además, porque estos dos países han sido bastante proactivos diplomáticamente ${ }^{8}$ hablando, por ejercer un mayor liderazgo en la discusión alrededor del deber ser de la CSS y, asimismo, han emprendido importantes proyectos a través de los cuales se han ido posicionando en sus temas con un mayor grado de expertise, lo que les permite ser referentes en CSS, que en el caso de Brasil ha sido principalmente en desarrollo y de Colombia en seguridad. ${ }^{9} \mathrm{Y}$ aunque persiguen el mismo objetivo en cuanto a mejorar las condiciones sociales propias y de sus socios, el desenvolvimiento de sus agendas en materia de política exterior los muestra como agentes divergentes que han construido distintas identidades alrededor de una misma idea de emancipación.

El rol que cada uno de estos países representa en materia de cooperación al desarrollo no resulta ser del todo igual u horizontal como pretende ser la CSS; en la práctica, las jerarquías del sistema continúan predominando, tal es el caso de la CSS desarrollada por Brasil (una potencia regional) respecto de los Países Africanos de Lengua Oficial Portuguesa (Palop) ${ }^{10}$ y Colombia (una potencia secundaria) con los países de la región mesoamericana. ${ }^{11}$

Retomando el análisis, es preciso señalar que este artículo de reflexión analiza el caso de la CSS gestionada por Brasil y Colombia desde el enfoque constructivista. Pues, como se ha venido describiendo, la CSS, en especial la desarrollada en Suramérica, ha sido producto de la construcción de ideas que se han fortalecido a través del discurso de una identidad marcada por aparentes características comunes de orden social y económico, a lo cual se le suma el factor de que en su gran mayoría se encuentran en la categoría de países de renta media, ${ }^{12}$ con altos niveles de desigualdad en sus fronteras y con la inmensa necesidad de diversificar sus lazos comerciales, así como de ampliar su eje de influencia, aunque desde diferentes niveles de actuación.

Este artículo ofrece un análisis y algunas reflexiones de la CSS implementada por Brasil y Colombia en el periodo de 2005 a 2015, por lo cual se estructura en cuatro partes. La 
primera describe la construcción de la CSS, así como su evolución conceptual, con miras a identificar las identidades de Brasil y de Colombia dentro del sistema internacional de cooperación y su posicionamiento en materia de CSS. La segunda analiza el caso de Brasil como global player de la CSS, así como los lineamientos de su política exterior y su "nuevo desarrollismo". La tercera se propone analizar cuál ha sido el resultado del despliegue diplomático de la CSS colombiana y qué lugar ocupa Colombia dentro de la región en su doble rol de donante/receptor. Por último, la conclusión revisa la identidad y la expertise institucional como dos factores de análisis para la comprensión del rol y posicionamiento de cada país en el sistema internacional de cooperación al desarrollo.

\section{La evolución de la CSS y su construcción conceptual}

Este apartado tiene como objetivo introducir los principales elementos históricos y conceptuales de la CSS que permitan entender cómo y por qué su discurso se ha ido transformando a la par con la construcción política del concepto alrededor del Sur global, entendido, inicialmente, como un grupo de países con altos índices de desigualdad, que comparten un pasado colonial. Concepto que, según la Enciclopedia de estudios globales, está asociado con movimientos trasnacionales antisistémicos y, por tanto, "un concepto político con raíces teóricas informadas por patrones globales de la dominación y la resistencia que va más allá del primer mundo centrado en el tercer mundo o dicotomías mundiales" (Anheier y Juergensmeyer, 2012, p. 725). ${ }^{13}$

No obstante, la definición anterior no resulta ser suficiente. Cabe aclarar que sobre la noción del Sur global y su construcción conceptual existen diversos debates, los cuales, entre otros análisis, buscan determinar si esta connotación que abarca un amplio, complejo y heterogéneo grupo de países es la adecuada o no. Ahondar en esta reflexión no es objeto de interés dentro de este análisis y, por tanto, se adoptará una definición más amplia utilizada por Ayllón (2013) de entender el Sur global como "una designación simbólica para denominar a una amplia gama de naciones en desarrollo, diversas por sus historias, orígenes y tradiciones, con múltiples enfoques en lo relativo al poder, la cultura y la identidad" (p. 15).

A partir de esta idea del Sur global, se desprenden distintas definiciones sobre la CSS, las cuales no solo responden a diversos enfoques teóricos, sino también a diversos intereses tanto políticos como económicos. En esa línea, resalta Ojeda (2016) que

desde los foros habituales de los actores asociados al CAD-OCDE ${ }^{14}$ se hace énfasis en la idea de CSS como una modalidad eminentemente técnica; en los foros de los PRM [países de renta media] se enfatiza a la CSS como prioritariamente económica; desde las Naciones Unidas se concentran en la idea del intercambio de experiencias, y en los espacios regionales y de integración se insiste en la CSS como un instrumento político de cambio. (p. 114) 
Parte de la construcción ideológica alrededor de la CSS tiene un importante enfoque sociológico, pues su definición desde diversas ópticas ha dependido "sobre todo de ideas, valores, normas, instituciones, identidades, intereses, significados intersubjetivos e intencionalidades colectivas" (Ibáñez, 2015, p. 190), todas ellas características del constructivismo social presentes en la CSS. Frente a la concepción de la identidad cabe anotar que esta "tiene un carácter inherentemente relacional, es decir, se es algo en referencia a otros y en contexto determinado" (Santander, 2016, p. 55).

A pesar de existir distintos enfoques y definiciones alrededor de la CSS, esto no ha evitado la construcción de una idea alrededor de dicho concepto como un instrumento emancipatorio, del cual cada agente busca alcanzar distintos intereses, pero a través de un comportamiento cooperativo. Basados en el argumento central del constructivista Alexander Wendt (1992), los agentes actúan sobre los objetos (la CSS, vista como instrumento) y hacia los demás (sus socios), dependiendo del valor que el objeto o los otros tengan para él, siendo la estructura la que define "el marco de oportunidades y limitaciones con el que se encuentran los agentes para desplegar sus acciones, son estos, los que a través de sus propias prácticas y comportamientos, se encargan de reproducir o transformar dicha estructura" (Santander, 2016, p. 52).

En este sentido, y desde una perspectiva interaccionista-normativa, ${ }^{15}$ la estructura de la CID será el propio sistema de cooperación al desarrollo que impera desde 1947, cuando se implementó el Plan Mashall. Desde entonces, la cooperación para el desarrollo se ha consolidado como "un régimen internacional que surge como resultado de la coordinación de políticas entre dos o más países ante la necesidad de reducir los costos de transacción" (Malalcaza, 2014, p. 171), una estructura que, como se ha venido señalando, se ha venido transformando y dentro de la cual entra la CSS, que es una modalidad complementaria a la tradicional cooperación Norte-Sur y que, por tanto, hace parte del mismo sistema (Ojeda, 2016).

Contrario a lo que se analiza sobre la CID, la CSS debe analizarse desde una perspectiva narrativa, en la que "los intereses y las identidades de los Estados son producto de procesos históricos específicos y de las percepciones que respectivos hombres de Estado tienen respecto del contexto internacional” (Malalcalza, 2014, p. 167), argumento que sirve para explicar el comportamiento de la CSS tanto de Brasil como de Colombia en las últimas dos décadas.

Por ello, se presenta una descripción de los principales hechos históricos que han contribuido a la construcción de identidades en estas estructuras, a partir de la idea de que el rol de estos países se construye socialmente y que su posicionamiento dependerá en últimas del reconocimiento que los otros hagan frente a este, ya sea a nivel regional, ya sea a nivel global (Hurell, 2000). 


\section{Evolución}

El desarrollo de la CSS se remonta a 1954 cuando Tailandia establece los primeros acuerdos de cooperación técnica con sus vecinos (Ojeda, 2016), la cual se replicó por otros países de la región como la India, Corea y Singapur para el intercambio cultural y de conocimientos. A partir de entonces, está práctica se dinamiza y, en diversos encuentros internacionales, los países del entonces llamado tercer mundo (Mignolo, 2011) empiezan a buscar mayores espacios para la consolidación de alianzas Sur-Sur encaminadas, principalmente, a la cooperación para el desarrollo. Frente a esta idea, es preciso señalar que tales procesos siempre van acompañados del interés por expandir y fortalecer lazos comerciales.

Posteriormente, la Conferencia de Bandung, celebrada en 1955, representa un importante hito para la CSS. Tras esta conferencia, se establecen los diez principios que regirían las relaciones de cooperación y amistad entre los países en desarrollo, principios que hoy en día refuerzan la noción de la CSS, tales como el respeto a la soberanía (no injerencia en los asuntos internos de otros Estados), la solidaridad (no condicionalidad de la ayuda) y la horizontalidad (ejecutada entre iguales o entre países socios). ${ }^{16}$ A causa de este importante encuentro, en 1961, reunidos nuevamente en la Conferencia de Belgrado, se funda el Movimiento de los No Alineados, un "foro de concertación política para los países del sur" (Cancillería, s. f.).

Otro importante antecedente ocurrió en 1964 con la creación de la Conferencia de las Naciones Unidas para el Comercio y el Desarrollo (UNCTAD 'United Nations Conference on Trade and Development'), cuyo resultado es la firma de la Declaración de los Setenta y Siete, conocido hoy en día como el G77+China, órgano intergubernamental en el que participan 131 países en desarrollo (The Group of 77 at the United Nations, s. f.). A través de este, se busca proporcionar "los medios para que los países del sur puedan articular y promover sus intereses económicos colectivos y mejorar su capacidad de negociación conjunta sobre los principales temas económicos internacionales [...] y promover la CSS" (Cancillería, s. f.).

Estos espacios de integración entre países en desarrollo iban de la mano de los intereses y las funciones atribuidas por la Carta de San Francisco a la Organización de las Naciones Unidas (ONU), en pro del fomento de la CID en beneficio de los pueblos, razón por la cual, desde el Consejo Económico y Social (Ecosoc), se buscaba dinamizar los temas propios del desarrollo, en especial en la década de los setenta, cuando el número de Estados miembros de la ONU se multiplica (que pasó de 51 en 1945 a 124 en 1980), debido al proceso de descolonización que se gestó, principalmente, en el continente africano durante la década de los sesenta.

Como respuesta a lo anterior, la Asamblea General de la ONU crea en 1974 la Unidad Especial para la Cooperación Técnica entre los Países en Desarrollo dependiente del 
Programa de las Naciones Unidas para el Desarrollo (PNUD), que en 2003 mediante la resolución 58/220 de la Asamblea General pasó a llamarse Unidad Especial para la Cooperación Sur-Sur y que desempeña un importante papel en la consolidación y difusión de buenas prácticas desarrolladas por casi 130 países del Sur global, pero que al mismo tiempo carece de instrumentos.

Y si bien estos hechos son significativos para ir construyendo la idea de fortalecer modalidades alternativas a la tradicional cooperación Norte-Sur, no es sino hasta la celebración de la Conferencia de las Naciones Unidas sobre Cooperación Técnica entre los Países en Desarrollo, celebrada en Argentina en 1978, que se toma la iniciativa de institucionalizar y coordinar los esfuerzos de los países en desarrollo en beneficio de un desarrollo conjunto, compromisos que se plasmaron en lo que hoy en día se conoce como el Plan de Acción de Buenos Aires (PABA). Desde entonces, se reconoce la necesidad de consolidar la CSS y de apropiar a los propios países del sur en sus procesos de desarrollo, desde la formulación hasta la ejecución de sus políticas locales con acompañamiento de un país socio que cuente con algún grado de expertise en el tema.

No obstante, en el caso de América Latina, las dos décadas siguientes a la aprobación del PABA estuvieron marcadas por inestables periodos económicos, dictaduras, surgimiento de guerrillas y del narcotráfico, este último fenómeno en países de la región andina, lo que hizo que la atención de todos los países se centrara, principalmente, en la solución de sus problemas internos.

Se constituye este en un periodo de altibajos para la consolidación de la CSS, que no se estabilizó sino hasta el fin de la Guerra Fría, momento en el que cambia el panorama para Suramérica, y se desarrolla un ambiente propicio para retomar la idea de fortalecer la CSS, todo ello motivado por un espíritu colectivo, enfocado en priorizar el desarrollo en la agenda internacional, así como en reforzar alianzas en el ámbito económico a través de las cuales posicionar a los Estados a nivel regional. Tal fue el caso de Brasil, que, para la década de los noventa, sufre importantes transformaciones a nivel interno reflejadas en su actuar externo.

El crecimiento y posicionamiento de estos países emergentes es una de las principales transformaciones en el sistema internacional de inicios del siglo XXI. Los ya mencionados países del IBSA, por ejemplo, fortalecen políticas internas para la ejecución de proyectos de la CSS como parte de su estrategia de inserción al mercado global con miras a obtener un mayor reconocimiento, motivo por el cual el discurso político resulta ser un importante elemento cohesionador dentro del Sur global.

"Los tres gobiernos coinciden en las grandes líneas de sus políticas: la promoción de la democracia, la paz y la estabilidad; el desarrollo sostenible; la lucha contra el hambre, la pobreza y la desigualdad social" (John de Sousa, 2007, p. 36), lo que evidencia que desde su integración hasta la fecha han buscado dinamizar sus políticas de cooperación hacia los países del sur alrededor de esos tres ejes. 
Complementario a ese proceso y adelantado por las potencias regionales emergentes, puntualmente en el caso que se analiza de Brasil, las potencias secundarias en Suramérica, Argentina, Chile, Colombia y Venezuela (Flemes, 2012a), también contaron con óptimas condiciones económicas, hecho que les brindó un espacio para diversificar su agenda en materia de política exterior, al consolidar el discurso sobre la CSS como un factor clave para fortalecer su identidad y ampliar de esta forma sus lazos sociales, comerciales y políticos con sus vecinos, a través del intercambio de experiencias y conocimientos adquiridos por sus instituciones; es decir, su expertise institucional, en busca de espacios autónomos fuera del eje de influencia de la potencia regional.

Schenoni (2014) señala que, a medida que Brasil incrementa su poder a nivel global, las potencias medias de la región buscan salvaguardar su autonomía. Si bien estos países reconocen a Brasil como un socio importante, comercialmente no dependen de este, pues su agenda comercial es mucho más diversificada, tanto respecto de aliados para la cooperación al desarrollo como de socios comerciales estratégicos.

En cuanto a la evolución de la CSS en Suramérica, ha sido una construcción narrativa que desde el discurso resalta la necesidad de que los propios países de la región sean agentes activos de sus procesos de desarrollo. En parte como respuesta a los cambios del sistema, pero también como estrategia para responder a la sutil disminución de los flujos de ayuda oficial al desarrollo (AOD) sufridos en un amplio grupo de países clasificados por el Comité de Ayuda al Desarrollo (CAD) como países de renta media alta, tal como se muestra en la figura 1.

\section{Figura 1 \\ La AOD bilateral por grupo de ingresos (2004- 2014) según la clasificación del CAD}

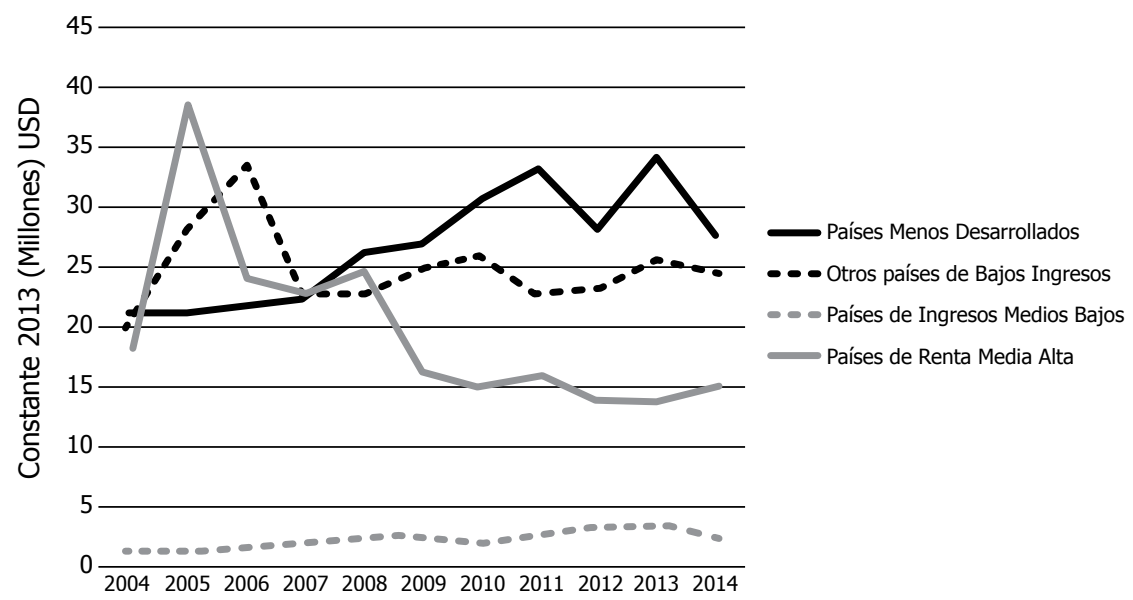

Fuente: OECD (2016, p. 157). 
Un ejemplo de lo anterior es el caso de Suramérica, donde la mayoría de los países de la región durante la primer década del siglo XXI hicieron la transición de países de renta media baja hacia países de renta media alta, razón por la cual la AOD ha ido disminuyendo paulatinamente en países como Argentina, Chile, Perú y Venezuela; contrario a lo que ocurre en Colombia, que, aunque también se encuentra en el grupo de países de renta media alta, su situación de conflicto interno lo ha hecho foco de importantes flujos de cooperación al desarrollo, al tiempo que empezaba a gestionar de manera más activa su CSS. Otro es el caso de Bolivia que, junto con Paraguay, siguen siendo países de renta media baja, según el CAD (véase figura 2).

\section{Figura 2 \\ La AOD recibida por países de Suramérica (2000- 2015). Porcentaje del PIB per capita}

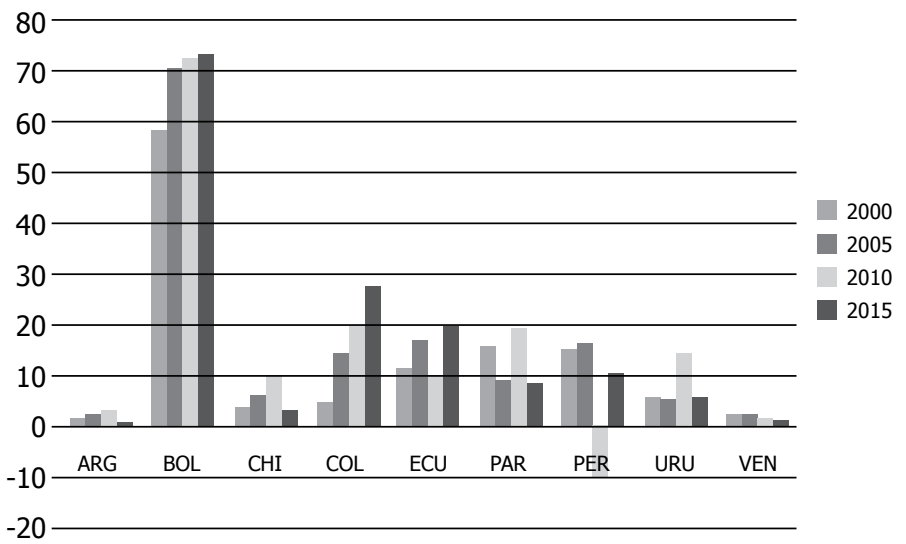

Fuente: Elaboración propia a partir de World Bank (s. f.).

No obstante, a pesar de todo lo señalado y frente a las enormes oportunidades que se presentaron en América Latina para empezar a gestionar la CSS como mayor grado de autonomía y diversidad de temas, las situaciones políticas actuales de algunos países que tradicionalmente eran grandes “donantes”, como Venezuela y Brasil (Ayllón, 2017), están empezando a evidenciar otros escenarios, en los que pareciera que el gran impulso por consolidar la CSS se está perdiendo y algunos países, incluso, regresan a la tradicional cooperación en busca de reforzar la cooperación triangular para no perder el estatus de donante/receptor. Tal es el caso de Chile, por ejemplo.

\section{Brasil, global player de la CSS}

Hasta este punto, se ha señalado que Brasil es considerada una potencia regional emergente. Las potencias regionales emergentes, según Nolte, “se caracterizan por ser parte 
de una región geográfica bien definida, tienen la capacidad de enfrentar a cualquier coalición de Estados en la región, tienen gran influencia en asuntos de relevancia regional” (2006, p. 13), así como gran capacidad de actuación en el ámbito global. Definición que, en términos generales, hace referencia a una noción de región desde el punto de vista geográfico, que no necesariamente va ligado a una identificación ideológica.

Frente a esta última idea, podría desligarse una variable de análisis descrita como la capacidad de estas potencias regionales emergentes de ejercer su liderazgo o lo que, en últimas, Nolte denomina leading power (poder líder), tanto a nivel regional como global. Dicha capacidad se define dependiendo del grado de influencia de este actor en ese espacio geográfico y, por tanto, de un alineamiento (de los otros Estados) frente a sus políticas y ambiciones globales.

Un posicionamiento de líder que debe estar estrechamente ligado con la definición de su identidad y, por ende, de sus aspiraciones en el plano regional y global, que toma mayor relevancia en la forma como los otros lo perciben, siendo la identidad un factor clave de análisis dentro de las dinámicas de la CSS adoptadas por Brasil.

Con respecto al leading power ejercido por Brasil en la región, hay autores que señalan que el poder de Brasil es cuestionado por otros Estados en la región, a pesar de los esfuerzos diplomáticos emprendidos por el Gobierno brasileño en Suramérica, que no le han permitido alcanzar ni el apoyo ni el reconocimiento total en su región (Malamud, 2011). Malamud señala, por ejemplo, el escaso apoyo que ha recibido Brasil por parte de estos, para alcanzar sus aspiraciones globales, entre ellas, la de ser miembro permanente en el Consejo de Seguridad de la ONU, la de ocupar altos cargos directivos en algunas organizaciones internacionales, en las que otras potencias secundarias también le hacen contrapeso, presentando candidatos o manifestando su interés de apoyar a otros.

En palabras de Schenoni (2015), se evidencia en la región un contrabalanceo, por lo que podría decirse que la mejor manera de denominar el rol de Brasil en el ámbito regional sería el de potencia intermedia emergente, pues, como se analiza en este artículo, Brasil posee influencia a nivel internacional (Keohane, 1969, citado por Flemes, 2012a, p. 29), que en parte puede atribuírsele a la profesionalización de su ejercicio diplomático $\mathrm{y}$ al fortalecimiento de alianzas intrarregionales, alrededor de las cuales se "reconocen que no pueden actuar efectivamente en solitario" (Flemes, 2012a, p. 29), pero que a nivel regional logra avances y liderazgos ambiguos.

De lo anterior se desprende que Brasil ejerce dos tipos de identidades en materia de CSS. Por un lado, está el de potencia intermedia emergente, que busca mejorar su posicionamiento y reconocimiento a nivel regional a través de la cooperación técnica, y por otro, una cooperación más enfocada en una visión desarrollista y universalista caracterizada por su afán de ejercer un mayor liderazgo y de legitimar su poder con miras a proponer reformasal sistema, que son proactivos en diversos escenarios internacionales (Jordaan, 2003). 
Con fundamento de lo anterior, el rol de potencia emergente regional o intermedia "se define a base de sus recursos de poder y su autopercepción" (Nolte, 2006, p. 15), lo que, en últimas, y complementando las reflexiones en este sentido de Nolte, "son construcciones sociales, su valor analítico y su valor efectivo en la política internacional dependen de la aceptación de ese estatus y de la jerarquía correspondiente por parte de otros Estados" (p. 16).

Una vez definido el estatus de Brasil, este apartado busca analizar la CSS que ejecuta Brasil desde 2003 con miras a mejorar su statu quo como global player en los asuntos internacionales, en especial aquellos ligados con el desarrollo. La inserción de Brasil a través de la CSS es una estrategia de política exterior que le ha permitido transferir y compartir sus políticas sociales, así como ampliar sus vínculos comerciales.

Algunos autores señalan que la política exterior de Brasil se mueve entre el universalismo y la autonomía (Pastrana y Vera, 2012; Vigevani y Ramanzini, 2011), comportamiento que se replica, necesariamente, en la gestión de su política de cooperación al desarrollo, ya que existe un estrecho vínculo entre una agenda y la otra.

El uso de la expresión global player es cada vez más frecuente en la literatura académica tanto para hacer referencia a la inserción de Brasil en el escenario internacional como para describir sus intereses por fortalecer sus lazos interregionales en materia política y económica y alcanzar un mayor grado de reconocimiento y prestigio (Pastrana y Vera, 2012; Santander, 2016; Soares, 2005; Soares y Hirst, 2006).

Frente a este último planteamiento, se podrían destacar dos ideas: la primera es la necesidad de restablecer un nuevo orden mundial, dentro del cual se propone principalmente la reforma al Consejo de Seguridad de ONU, haciendo énfasis en la necesidad de ampliar la representatividad de sus miembros y darles una mayor voz a los países del Sur global, lo que se traduce en otorgarle a Brasil una silla como miembro permanente de este órgano, aspiración de Brasil desde el Gobierno del presidente Itamar Franco, cuando por séptima vez el país fue designado como miembro no permanente en el Consejo de Seguridad (1993-1994) (Vargas, 2000). Y la segunda, una fuerte apuesta por reestructurar el sistema económico internacional, en el cual se dé una verdadera apertura comercial que les permita a los países del sur competir en los mercados nacionales de los países del norte. En palabras del presidente Luiz Inácio da Silva (2005), no es otra cosa que garantizar un "sistema más equitativo, donde los flujos financieros y de comercio internacional creen oportunidades".

De ahí la dinámica actividad diplomática de Brasil en foros multilaterales, dentro de los cuales se destacan los que se hacen en el marco de la Organización Mundial del Comercio (OMC), los encuentros del G2o y en las reuniones anuales BRICS (Brasil, Rusia, India, China y Sudáfrica) y de IBSA. Todos estos encaminados a reorientar, reorganizar, el sistema económico internacional y financiero (Vigevani y Ramanzini, 2011). 
Por tanto, el término global player se usa en este artículo para comprender el lugar de Brasil dentro del sistema internacional de cooperación al desarrollo desde su rol de donante emergente. Frente a esta última idea, es necesario hacer dos aclaraciones: la primera es que es una expresión que el Gobierno de Brasil rechaza (Brígido Bezerra, 2016) por considerar que el uso de la palabra donante es una expresión propia de la Organización para la Cooperación y el Desarrollo Económico (OCDE), que, en el fondo, describe relaciones asimétricas, las cuales no suscriben la esencia de la CSS que este país pretende desarrollar, la cual es, en esencia, una cooperación entre socios, que en este análisis, visto desde una dimensión política, define el rol que actualmente representa Brasil, que, a pesar de rechazar el concepto, en la práctica lo evidencia, al establecer a través de su CSS relaciones asimétricas con los países de menor desarrollo relativo al suyo. Y la segunda idea alrededor del concepto de donante emergente es que se articula con las nociones del nuevo desarrollismo, apuesta del Gobierno brasileño que "considera que debe trabajar con otros países en desarrollo, persiguiendo intereses comunes y tratando de transformar el orden internacional" (Santander, 2016, p. 211), propósito que nace a partir del ascenso al poder de Luiz Inácio da Silva en 2003 como política de cooperación vigorizada, que se ha caracterizado, especialmente, por una mayor diversificación geográfica (Ramanzini, Passini y Ribeiro, 2015; Santander, 2016).

Según el Instituto de Pesquisa Económica Aplicada (IPEA), en el periodo de 2003 a 2013, Brasil desarrolló diversos proyectos con 159 países a través de cooperación técnica, es decir, aquella que se basa en la transferencia y el intercambio de conocimientos y experiencias entre países, e incluso a través de organismos multilaterales (Brígido Bezerra, 2016). La cooperación técnica busca "proporcionar conocimientos y habilidades técnicas y de gestión a los recursos humanos del país receptor” (Boni, 2010, p. 12), por lo cual hoy en día su agenda de cooperación es más diversa.

La cooperación técnica desplegada por Brasil entre 2011 y 2013 fue dirigida, principalmente, a temas vinculados con desarrollo social y lucha contra el hambre, desarrollo urbano e inclusión bancaria, derechos humanos, investigación agropecuaria, investigación económica y salud pública (Brígido Bezerra, 2016). En años recientes, "las políticas sociales de Brasil han sido objeto de internacionalización a través de programas de cooperación bilateral y multilateral” (Milani y Pinheiro, 2017, p. 287).

Cabe resaltar que en la cooperación ejecutada por Brasil en las políticas mencionadas, han participado directamente órganos del Gobierno federal, tales como Ministério das Relações Exteriores, Ministério de Assistência Social, Ministério do Desenvolvimento Social e Agrário, Secretaria de Direitos Humanos da Presidência da República, entre otros, e incluso órganos de la Administración pública federal (Brígido Bezerra, 2016).

Su aspiración por ser un global player busca ser alcanzada a través del soft power que ejerce, dado que como parte de su estrategia ha estado la de no usar su poderío, en 
especial el militar (Soares y Hirst, 2006). Suramérica ha sido una región pacífica, por lo cual lo militar no resulta relevante para Brasil. Según cifras del Banco Mundial a 2015, en porcentaje del producto bruto interno (PBI), Brasil invirtió el 1,4 \%, que fue el de los más bajos respecto de otros países de la región como Chile (1,9\%), Bolivia (1,6\%), Perú (1,6 \%), Ecuador (2,7 \%) y Colombia (3,4 \%). Por debajo de Brasil solo está Argentina $(0,9 \%)$, lo cual es coherente si se tienen en cuenta los diversos compromisos adquiridos por ambos países "sobre la cooperación pacífica” (Vargas, 200o, p. 232).

Así es como la puesta en marcha de una agenda social dentro de los lineamientos de política exterior podría resaltarse como un ejemplo del soft power que ejerce Brasil a través de su CSS, e incluso "puede considerarse una innovación” (Soares y Hirst, 2006, p. 22), que además se favoreció gracias a un ambiente económico estable y políticamente activo (Ayllón y Costa; 2010; Ayllón, 2013; Santander, 2016; Soares, 2006), pero que también conlleva otra reflexión y es que puede volverse volátil ante los cambios estructurales del sistema.

El buen desempeño de indicadores económicos, así como la reducción de la pobreza y la desigualdad social, le dio al país una mayor proyección (Desiderá, 2015), lo que favoreció el diseño y la ejecución de una fuerte estrategia por alcanzar un mayor liderazgo regional, apostándole siempre a lo multilateral, a través de coaliciones sur-sur, que le permitan "coordinar posiciones y actuaciones conjuntas en los ámbitos de negociación multilateral de reglas que orientan la gobernanza global” (p. 213).

Actuar en el campo regional y desarrollar una especie de multilateralismo del sur a nivel global son dos objetivos consagrados en la Constitución de la República Federativa del Brasil de 1988, los cuales también orientan su cooperación por mandato constitucional, que lo diferencia de otros países de la región.

La República Federativa de Brasil se rige en sus relaciones internacionales por los siguientes principios [...] cooperación entre los pueblos para el progreso de la humanidad, [y prosigue], buscará la integración económica, política, social y cultural de los pueblos de América Latina, con vistas a la formación de una comunidad latinoamericana de naciones. (art. 4)

Frente a lo anterior, desde la década de los noventa, Brasil emprende diversas acciones diplomáticas y políticas que representan para el país enormes avances en materia de integración, pero, al mismo tiempo, grandes desafíos para su consolidación como líder regional, tarea que a hoy sigue sin concretarse.

\section{El Brasil donante y el Brasil receptor}

Hasta el momento, se han señalado dos grandes objetivos de la cooperación brasileña: el primero, su creciente participación en escenarios multilaterales y la diversificación de socios, y el segundo, el fortalecimiento de sus relaciones a través de proyectos de 
cooperación técnica con los países de la región, objetivos enmarcados alrededor de la idea de un "nuevo desarrollismo" (Santander, 2016).

Según el Banco Mundial, Brasil es un país de 207,65 millones de habitantes, con una extensión territorial de 8,6 millones de $\mathrm{km}^{2}$ y un PIB per capita de USD 8840,95 a 2016. Actualmente, está clasificado en la lista del CAD como PRMA, que, además, cuenta con grandes riquezas naturales y energéticas, que lo posicionan con fuerza en el escenario económico internacional.

Sin embargo, el gigante latinoamericano lleva los últimos tres años inmerso en una crisis política, que podría frenar su potencial o, al menos, su credibilidad internacional, a lo que también se suma una inadecuada distribución de los recursos y la corrupción política y privada que la hacen una sociedad con alta inequidad social, razón por la cual, a pesar de su interés por ser un líder regional y un referente en materia de CSS desligándose de su rol de "receptor", las cifras muestran un aumento de la AOD recibida por Brasil en los últimos cinco años respecto de los años de mayor auge de su CSS (entre 2003 y 2010) (ver figura 3).

Figura 3

\section{La AOD recibida por Brasil y las potencias secundarias de Suramérica (2000-2015). Porcentaje del PIB per capita}

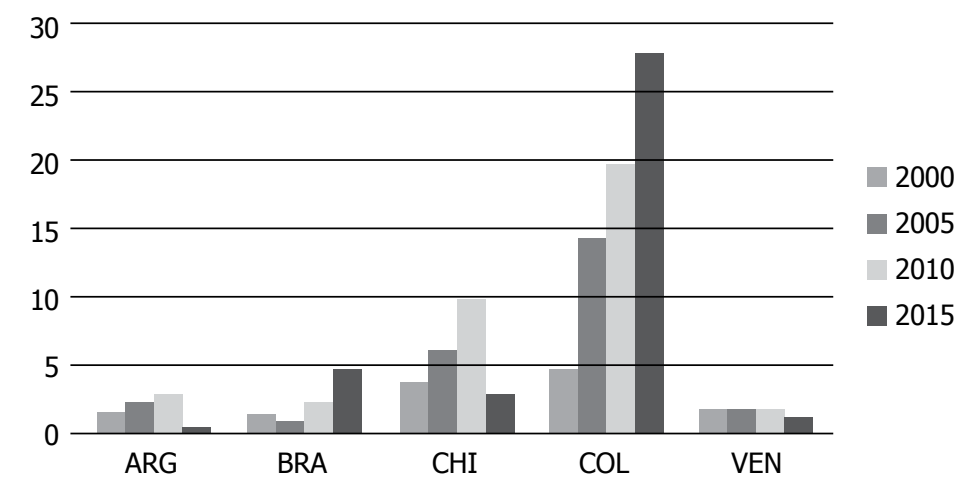

Fuente: Elaboración propia a partir de World Bank (s. f.).

Este incremento es justificado como parte de la estrategia de fortalecer la cooperación triangular (Hirst, 2010), en la cual Brasil recibe recursos financieros por parte de organismos internacionales y de países desarrollados (miembros del CAD), para ejecutarlos en proyectos sur-sur.

A 2005, Brasil recibió USD 196 millones de AOD, cifra que se redujo al año siguiente a USD 113 millones. En 2007 y 2008, se registró un repunte de la AOD (motivada por aportes de Japón y Alemania, países que incrementan su cooperación triangular), hasta un total de USD 32 millones y USD 460 millones (Ayllón, 2010, p. 3). 
Esta última reflexión se liga, entonces, con su nueva identidad de donante emergente, en la que ha buscado mantener su autonomía frente al sistema de cooperación impuesto por la OCDE desde la década de los sesenta, que legitima su presencia a través de proyectos de cooperación entre y hacia otras regiones, y fortalecer su apoyo económico a instituciones multilaterales como la ONU y dentro de organismos regionales como lo hace a través del Banco del Sur creado en 2014 a través de los BRICS (Santander, 2016).

Una de las características de la CSS es que los países comparten sus buenas prácticas, conocimientos y experiencias hacia otros. En el caso de Brasil, su agenda de cooperación social incluye campos como el agrícola (transferencias de tecnologías y técnicas de cultivo), salud pública y de inclusión social como los programas de transferencias condicionadas (PTC). Estos últimos han sido los programas líderes de la agenda de desarrollo de Brasil hacia sus socios, entre ellos, Programa Bolsa Família, Plano Brasil sem Miséria ${ }^{17}$ y Política de Segurança Alimentar e Nutricional (Desiderá, 2015).

Un estudio financiado por el programa EUROsociAL, coordinado por Tassara (2015), analiza, entre otros casos, los PTC desarrollados por el Gobierno de Luiz Inácio da Silva, los cuales fueron "concebidos con el propósito de transformar y detener la transmisión intergeneracional de la pobreza mediante el desarrollo de las capacidades humanas en las familias más vulnerables" (Cecchini y Madariaga, 2011, citado por Tassara, 2015, p. 20). Este estudio señala que tal tipo de políticas desarrolladas por Brasil lograron tener una "amplia incidencia sobre la consolidación de un modelo de desarrollo económico con inclusión social” (p. 31), cuyos resultados lograron "sacar a 28 millones de personas de la pobreza y empujar a otros 36 millones hacia una condición de clase media” (p. 31). Esta política social le permitió consolidarse en la región como líder de la lucha contra la pobreza; entre los principales socios receptores de esta experiencia están Chile, Colombia y Perú.

Para alcanzar un mayor grado de visibilidad y reconocimiento global, entre 2003 y 2013, Brasil incrementó su presencia en el continente africano, al ampliar sus proyectos de cooperación con 35 países africanos e invertir a 2009 cerca de USD 90 millones (Ayllón, 2010), enfocados, principalmente, en la cooperación técnica en los Palop (Ayllón y et al., 2010; Giacalone, 2013; Ramanzini y Ayerbe, 2015; Soares, 2005), en temas como investigación agropecuaria, salud pública, manejo de tuberculosis y programas de acción de vigilancia sanitaria (Brígido Bezerra, 2016), entre otras acciones puntuales que ejecuta en cada uno de estos países acorde con las necesidades del receptor.

Desde 2000, la estrategia de cooperación brasileña ha estado acompañada por el Banco Nacional de Desenvolvimento Econômico e Social (BNDES), el cual ha comenzado "a ocupar un lugar muy destacado de la cooperación financiera ofrecida por Brasil a otros países en desarrollo” (Santander, 2016, p. 202). Frente a la acción del BNDES, Ayllón señala que han sido desembolsados a través de esta institución 
3.300 millones de dólares [que] corresponden a los préstamos comerciales realizados en desarrollo [...] los préstamos del BNDES son de corte reembolsable y demandan la adhesión de los beneficiarios a varias condiciones, siendo la primera, la obligatoriedad de que los recursos sean utilizados para comprar bienes y contratar servicios de empresas brasileñas. (2010, p. 5)

Lo anterior muestra el rol de donante emergente de un Brasil que no solo expande sus lazos de cooperación y amistad, sino también sus industrias y su mercado, tema que ha sido estudiado en los últimos años con el objeto de identificar el impacto de la CSS tanto en el desarrollo del sector privado brasileño como en el de las principales empresas públicas del país. Frente a esto, es importante señalar que cada vez más se liga la cooperación de Brasil con la inserción de empresas brasileñas en África.

La concentración en países africanos desempeña no solo la función moral de rescatar “deudas históricas por su valiosa contribución a lo que hoy en día es la multiétnica nación brasileña" (Pereira de Fonseca, 2008, p. 67), sino que, incluso, como señalan Ayllón y Costa (2010),

también guarda relación con intereses económicos de Brasil, como los vinculados a la expansión de la producción mundial de biocombustibles, [...] con el apoyo del Gobierno, las empresas brasileñas del sector de la energía (Petrobrás), construcción (Odebrecht, Andrade Gutierrez, Camargo Correa) y minería (Vale do Rio Doce), entre otras, que han pasado a invertir cada vez más en el continente y en otras regiones en desarrollo. (p. 83)

En cuanto a América Latina, entre 2007 y 2017, la CSS brasileña hacia los países de Suramérica disminuyó, tal como se muestra en la figura 4. Este comportamiento parecería ir en contraposición del interés de Brasil por consolidar su poder o presencia en la región. Sin embargo, este comportamiento obedece, no enteramente, al fortalecimiento de la CSS por parte de las potencias medias como Colombia, Chile y Argentina, que también han fortalecido sus agencias de cooperación frente al tema y han dinamizado sus agendas entre ellos y hacia otros países de la región. 


\section{Figura 4 \\ Total de proyectos de CSS desarrollados por \\ Brasil en Suramérica entre 2007 y 2015}

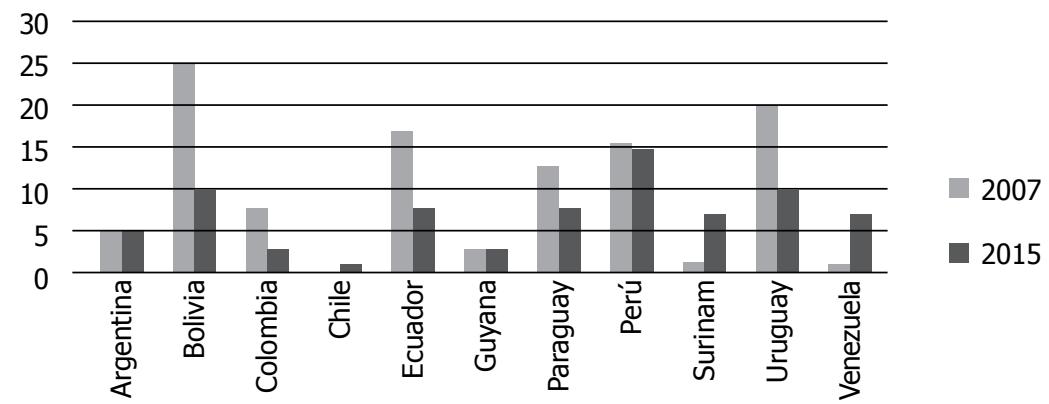

Fuente: Elaboración propia a partir de datos de Agência Brasileira de Cooperação (ABC, s. f.).

Finalmente, para resumir este apartado sobre el rol de Brasil como agente de cooperación al desarrollo, puede resaltarse que el gigante suramericano gestiona principalmente la cooperación técnica seguida de la financiera, donde la cooperación multilateral tiene un fuerte y significativo peso para poder expandir sus lazos comerciales y de cooperación a través de alianzas interregionales donde priman las coaliciones sursur. El modelo resultante de la cooperación brasileña es producto de la definición de su identidad, y puede definirse, en palabras de Santander (2016), como un "modelo de cooperación al servicio de la búsqueda de proyección global desde el sur” (p. 246).

\section{El despliegue diplomático de la CSS colombiana}

Hasta este punto, se ha analizado el rol y la importancia que las potencias intermedias emergentes como Brasil le dan a la CSS como un instrumento de inserción política y económica. En esa línea, se definió a partir de la identidad de global player del sur, factor que se acompaña tanto de la exportación de sus buenas prácticas y políticas internas como de su expertise institucional, que se consolida como un factor de posicionamiento en distintos ámbitos, en parte, por la cantidad de proyectos que pueden gestionar gracias al tamaño de su economía y porque han tenido una mayor presencia e injerencia en temas sobre desarrollo, comercio y economía. No obstante, las llamadas potencias secundarias también han venido con sus propias agendas, aprovechando y utilizando sus capacidades y desarrollando cierto grado de expertise institucional en temas más puntuales que las potencias intermedias emergentes.

Frente a la definición de potencias secundarias, Flemes (2012b) señala que estas "tienen una posición sistémica de dos caras: formulan sus estrategias de política exterior partiendo 
de la condición de inferioridad fáctica, percibida y/o anticipada con relación a la potencia principal, así como de superioridad respecto a los otros Estados de la región” (p. 21).

En los últimos años, la diplomacia colombiana ha venido desarrollando esfuerzos por diversificar los temas de la agenda de cooperación internacional al desarrollo, en busca de tener una mayor presencia y, por qué no decirlo, protagonismo en diversos encuentros multilaterales que sobre los temas de desarrollo se han realizado en la última década, como el Tercer Foro de Alto Nivel sobre la Eficacia de la Ayuda al Desarrollo, celebrado en Accra en 2008; la Alianza para la Cooperación Eficaz al Desarrollo, realizado en 2011 en Busán (Corea del Sur); o la Conferencia de las Naciones Unidas para el Desarrollo Sostenible, conocida como Río+20 en 2012, en los cuales se destacan los aportes del Gobierno colombiano frente al debate sobre la eficacia de la CID analizado en la introducción.

Durante los dos periodos presidenciales de Juan Manuel Santos (2010-2014, 2014hoy), el país ha mostrado un mayor interés por fortalecer los lazos regionales, en especial en el campo económico y político. Ejemplo de ello es la apuesta que hace a través de la Alianza del Pacífico, ${ }^{18}$ con lo cual demuestra que la política exterior colombiana, en parte, se ha impulsado debido al "proceso de internacionalización de la economía colombiana [...] así como [a] las múltiples transformaciones de las que ha sido testigo el sistema internacional" (Ardila, Cardona y Tickner, 2002, p. 18) y de las que Colombia se ha beneficiado.

Entre los cambios más representativos, y que tienen estrecha relación con la evolución de la CID del país, se encuentra el incremento en la participación de actores no estatales, los cuales también junto con el Gobierno gestionan recursos de cooperación en diversas temáticas que le apuntan a una mayor inclusión social. Sin embargo, frente al trabajo que realizan unos y otros, hace falta una mayor sinergia. Estas organizaciones abogan por una mayor participación y reconocimiento, y las OSC en Colombia realizan actividades que favorecen la imagen positiva del país y gestionan su cooperación alrededor de diversos temas de trabajo, al realizar una especie "de soft power que el gobierno parece ignorar que tiene" (Marín, 2017, p. 239).

Por otro lado, así como se han diversificado los agentes, los temas en la agenda internacional del país también lo han hecho. Durante el Gobierno del presidente Santos, la política exterior del país se ha ido alineando con los compromisos internacionales adquiridos por el país en materia de desarrollo, ejemplo de ello son los ODS, los cuales hacen parte del Plan Nacional de Desarrollo 2014-2018 Todos por un nuevo país: paz, equidad y educación, el cual cuenta con mecanismos para su implementación, financiación y seguimiento, lo que es un importante avance en la gestión pública frente al cumplimiento de los ODS.

El presidente Juan Manuel Santos reconoce que la CID 
actor internacional con peso específico, que extiende sus manos también para aportarle al progreso de otros [...] hemos dejado de ser monotemáticos, porque nuestra agenda internacional, que se concentraba en asuntos como la lucha contra el terrorismo, la lucha contra el narcotráfico, ahora tiene una agenda mucho más diversificada, ya hablamos de desarrollo social, de medio ambiente, de ciencia y tecnología, mientras antes pedíamos cooperación para la lucha contra las drogas ilícitas, ahora nuestro país es requerido para cooperar. (“Palabras del presidente Juan Manuel Santos durante la presentación de la Agencia de Cooperación Internacional”, 2012)

Lo anterior evidencia el “desdibujamiento de las fronteras entre política doméstica e internacional" (Ardila, Cardona y Tickner, 2002, p. 18), reflexión que lleva a reconsiderar un concepto abordado en la década de los noventa, en el cual "lo que se trataría sería proyectar y consolidar el réspice varia et mutabilia (mira lo que es diverso y cambiante), como la conducta probablemente más óptima y audaz en el actual concierto global” (Cardona y Tokatlian, 1991, p. 152), para describir los roles ejecutados por Colombia en materia de CID y la diversificación de su agenda, así como la paulatina transformación de su identidad a lo largo de las dos últimas décadas.

Esto no quiere decir que en la definición de los temas de la agenda el país haya dejado de tener un "carácter presidencialista" (Cardona y Tokatlian, 1991; Ardila, Cardona y Tickner, 2002; Borda et al., 2011), postura que, sin duda, ha definido la política exterior del país. Esta característica también ha sido evidente en el manejo que se ha venido gestionando de la cooperación al desarrollo, la cual no ha pasado de ser una agenda pública, y si bien es un tema de alto interés político al que le ha dado mayor visibilidad (Cobb, Ross y Ross, 1976), por ser necesariamente un vehículo para apoyar la implementación de los acuerdos de paz de La Habana, sigue siendo coyuntural. Por tanto, su prioridad es algo transitorio que puede correr el riesgo de pasar a un segundo plano ante un cambio, o bien en las prioridades del Gobierno, o bien en un cambio de este, tal como ha ocurrido desde sus inicios con la institucionalidad de la CID en el país.

En 2005, la Agencia Colombiana de Cooperación Internacional, que había sido creada en 1997 y dependía del Departamento Nacional de Planeación (DNP), pasó a manos del Ejecutivo al crearse la Agencia Presidencial para la Acción Social, que funcionó bajo este nombre hasta 2011, cuando en el Gobierno de Juan Manuel Santos y mediante el Decreto 4152/2011, de 3 de noviembre, se da inicio a la Agencia Presidencial de Cooperación Internacional de Colombia (APC-Colombia).

APC-Colombia es una "entidad descentralizada de la Rama Ejecutiva del orden nacional, con personería jurídica, autonomía administrativa y patrimonio propio, adscrita al Departamento Administrativo de la Presidencia de la República”, además la CID es una prioridad para el Estado colombiano como objetivo de su política exterior y de desarrollo 
para "alcanzar la proyección internacional [...], mediante la diversificación temática y geográfica, así como una inserción positiva en los escenarios mundiales" (Decreto 4152/2011, 3 de noviembre), aparte de visibilizar y posicionar al país como oferente.

Una de las estrategias implementadas por Colombia durante el segundo mandato de Juan Manuel Santos ha sido alinear la cooperación internacional alrededor de una cooperación para la paz, que se enmarcó en lo que se conoce como Hoja de ruta de la cooperación internacional en Colombia 2015-2018 (APC-Colombia, 2015), la cual gira alrededor de tres áreas prioritarias: 1) construcción de paz, 2) desarrollo rural sostenible y 3) conservación y sostenibilidad ambiental. ${ }^{19}$ Frente a esta estrategia, por ejemplo, el Gobierno colombiano logró alinear la AOD, la cual está dirigida a la implementación de los acuerdos de paz.

Según el Informe de gestión 2016 sobre el estado de la cooperación en el país, presentado por la APC-Colombia, el país ha recibido USD 635 millones, que, en las áreas de la hoja de ruta de la cooperación, se han distribuido de la siguiente manera: construcción de paz $69 \%$, desarrollo rural sostenible $24 \%$ y conservación y sostenibilidad ambiental 3 \% (APC-Colombia, 2016). Estas cifras muestran que la prioridad para Colombia sigue estando alrededor de los temas de paz y seguridad, que vinculan todas aquellas acciones relacionadas con reconciliación, atención de víctimas y proyectos alrededor de fortalecimiento de la justicia, reparación integral de las víctimas, restitución de tierras, desminado y fortalecimiento de la memoria histórica (APC-Colombia, 2015).

Frente a su rol de donante, el mismo informe señala que para 2016 Colombia cooperó con 61 países, a través de 63 proyectos. Al igual que la cooperación brasileña, la participación de las entidades del orden nacional colombiano, dada su experiencia, se consolida como un factor clave para el fortalecimiento de las estrategias en materia de CSS, en el que se destaca dentro de dicha expertise institucional el trabajo del Ministerio de Relaciones Exteriores, la Universidad Nacional de Colombia, el Ministerio de Cultura, el Ministerio de Tecnologías de la Información y las Comunicaciones, el Servicio Nacional de Aprendizaje (SENA), entre otras.

Con respecto a los socios beneficiarios, las principales acciones han estado dirigidas hacia Centroamérica y el Caribe, con alrededor de 22 proyectos ejecutados (APC-Colombia, 2016b), a través de las siguientes líneas: promoción social, gestión de calidad, servicios púbicos, gobernabilidad social, seguridad y apoyo a las medianas y pequeñas empresas (Cancillería, s. f.).

En cuanto a los intereses frente a la CSS, Colombia busca volverse un aliado estratégico en la región (Sanín, 2010), en especial en temas de seguridad, un campo en el cual el país ha adquirido cierta expertise que lo vuelve referente, que se enmarca en su dualidad de receptor/donante, en el que se observa la importancia que para el país tiene la cooperación triangular. Esto último se refleja en la proximidad de los gobiernos colombianos hacia 
los Estados Unidos en temas de seguridad y cooperación militar, como lo fue durante el Gobierno de Álvaro Uribe Vélez, por ejemplo, donde "la política exterior fue en gran parte instrumentalizada para cumplir con las prioridades de la política interna en el marco del Programa de Seguridad Democrática” (Flemes, 2012b, p. 32), lo que aisló regionalmente al país durante un periodo y securitizó la agenda de cooperación del país.

Ligado a lo anterior, Tickner y Morales (2015) retoman el concepto de cooperación dependiente asociada para definir el rol de Colombia frente a su estrategia de seguridad y su política de CSS, en la cual "la exportación de la seguridad [...] es producto de la triangulación con Estados Unidos [...] [al definirla como] una relación más estratégica y de menor subordinación” (p. 171), estrategia a través de la cual el país busca obtener un mayor reconocimiento en su rol de oferente, donde sus principales socios son aquellos países con situaciones similares y cuyas amenazas provienen del narcotráfico, las drogas y la violencia en todas sus formas, siendo por tanto los principales receptores beneficiarios de la expertise institucional colombiana, resultado de la triangulación con los Estados Unidos (Tickner y Morales, 2015).

\begin{abstract}
Santos [...] colocó en el centro de la política exterior de Colombia la cooperación internacional en seguridad [...]. La iniciativa se bautizó Estrategia de Cooperación Internacional en Seguridad Integral, y el Ministerio de Relaciones Exteriores de Colombia fue encargado de interactuar con los gobiernos extranjeros y coordinar los esfuerzos específicos de cooperación con el Ministerio de Defensa, la Policía Nacional y la Agencia Presidencial de Cooperación Internacional. (Tickner y Morales, 2015, p. 194)
\end{abstract}

La Estrategia nacional de cooperación internacional 2012-2014 (APC-Colombia, 2012a) fue diseñada, según información de la Cancillería, por el Ministerio de Relaciones Exteriores, el Ministerio de Defensa Nacional y la Policía Nacional, en busca, principalmente, de "aumentar al máximo la efectividad en la lucha contra la delincuencia organizada trasnacional”. Dentro de este tipo de estrategia, el Gobierno de Colombia prioriza la modalidad de cooperación triangular, en la que sus socios estratégicos han sido los Estados Unidos y Canadá, la cual se centra en siete componentes: 1) desarrollo organizacional, 2) lucha contra las drogas, 3) lucha contra la delincuencia, 4) seguridad ciudadana, 5) anticorrupción, 6) derechos humanos y derecho internacional humanitario y 7) fortalecimiento de capacidades de entrenamiento, inteligencia, combate y fuerzas especiales de las Fuerzas Armadas, de la Policía Nacional y entes de control y seguridad, experiencias que se han compartido, principalmente, con países de la región mesoamericana y con países andinos.

Aquí, se quiso cuestionar el rol del país frente a la CID, la cual resulta ser ambigua con altos grados de incertidumbre. La visión de Colombia frente al desarrollo ha estado ligada a la percepción manejada por la comunidad internacional, según la cual no puede existir 
desarrollo si no hay seguridad. Una mirada realista tal vez, que pregona por la garantía de ambientes libres de violencia, para garantizar entornos seguros, que den espacio al crecimiento social y económico. No obstante, se cuestiona hasta qué punto esta "securitización de la cooperación" pueda considerarse desarrollo, y si realmente Colombia ha adquirido la experiencia suficiente para exportar o compartir lo que aún no es, un país seguro.

\section{¿Colombia hacia la OCDE?}

Con miras a ese cambio de política exterior que se señaló, el país empezó a tener, con la llegada de Juan Manuel Santos al poder, la priorización de su imagen en el exterior y la consolidación en la región, de alianzas sur-sur más sólidas en términos comerciales y formulación de políticas que le han permitido ganar espacios de concertación sobre diversos temas, para la diversificación de su agenda.

Gracias a lo anterior, en 2013, el país solicitó su adhesión a la OCDE y ese mismo año la organización aceptó la candidatura de Colombia, que, aunque no significa que ya sea miembro, implica que el país cumpla con una serie de tareas y de "requisitos" que le permitirán ser parte de este selecto grupo, hecho que para el Gobierno nacional es visto "como una de las vías multilaterales para expandir su comercio, aumentar su confiabilidad para la inversión externa y percibir más cooperación técnica” (Pastrana y Vera 2012, p. 221), lo cual explicaría el interés de esta administración por ser más activo en su doble rol de oferente y demandante.

Desde entonces, el país ha venido direccionando sus esfuerzos institucionales para alcanzar esta ambiciosa meta de pertenecer a la organización de los cooperantes. Entre algunas de las ventajas que podrían señalarse, la más importante para un país con las condiciones socioeconómicas como las de Colombia es que a través de la OCDE podrá recibir un mayor acompañamiento para el desarrollo de sus capacidades locales, lo que le permitirá orientar mejor el diseño de sus políticas púbicas. No obstante, este ingreso también exige que el país replantee su rol dentro del sistema internacional de cooperación al desarrollo y modifique sus comportamientos internos para logar construir alianzas más sólidas para el desarrollo.

Colombia se encuentra en proceso de definición no solo de su rol, sino incluso de su identidad, según señalan algunos autores. La política exterior del país se ha venido desarrollando entre dos tipos de comportamientos: subordinación y autonomía (Ardila, Cardona y Tickner, 2002; Borda et al., 2011), y al igual que Brasil, estos comportamientos se reflejan en el manejo que hace el país de su política de CID. Frente a la subordinación en el manejo que se hace de la cooperación, puede decirse que Colombia "busca mantener abierta la posibilidad de seguir recibiendo AOD” (Hirst, 2010, p. 21) y, por tanto, sus políticas internas estarán alineadas con su agenda internacional y los intereses del Gobierno por darle fin a la situación de conflicto a través del apoyo internacional (Sanín, 2010). 
Para Hirst (2011), una característica de Colombia frente a la ejecución de la CID ha sido la constante búsqueda por "perfeccionar instrumentos y mejorar resultados de la ayuda internacional” (p. 553), de ahí la importancia de fortalecer nuevos espacios de acción y de gestión política para el desarrollo de proyectos autónomos en materia de cooperación.

Hirst destaca en su análisis el hecho de que el peso de la AOD dentro de la economía colombiana es bastante limitada, "la AOD corresponde a menos del o,5 \% del PIB" (2011, p. 573), lo cual pone en evidencia que, a pesar de lo que se cree, Colombia no es dependiente de la ayuda financiera internacional, pues, si bien este monto en cuanto a recursos financieros no es alto, la cooperación técnica que recibe el país sí lo es, ejemplo de ello es lo que se ha venido mencionando en materia de seguridad.

Este hecho da paso al desarrollo de políticas autónomas. La ayuda que Colombia recibe también se redirige a diversificar la agenda de CSS a través de cooperación triangulada, en la que prima un comportamiento casi que subordinado, pero al mismo tiempo autónomo; por lo que se ha venido mencionando, "la cooperación internacional en seguridad se ha desarrollado en función de la relación de Colombia con Estados Unidos" (Tickner, 2016, p. 10).

Por tanto, para alcanzar esa autonomía, el país ha venido fortaleciendo otras áreas de actuación distintas de los temas de seguridad, tales como "modernización del Estado, desarrollo y población, educación y agua potable y saneamiento básico, medio ambiente y agricultura y es un receptor en temas de derechos humanos, medio ambiente, desarrollo alternativo, desarrollo social, paz y desarrollo regional” (Hirst, 2011, p. 578), temas que negocia y ofrece a través de las comisiones mixtas de cooperación técnica y científica que son creadas a través de convenios marco de cooperación (Cancillería, s. f.).

Dinámicas que no son exclusivas de la Administración Santos, ya que empezaron a gestionarse desde 2002, durante el Gobierno de Uribe, cuando se diseñó la Estrategia de Cooperación 2002-2006, en la cual se destaca por primera vez a la CSS como lineamiento de la política exterior del país. Durante este periodo, Colombia "contaba con 16 convenios de cooperación, que se reflejaron en 252 actividades de oferta y 115 de recepción, estas últimas principalmente de países como México, Brasil, Argentina y Chile" (Sanín, 2010, p. 116).

Ampliando el alcance dado durante el Gobierno de Uribe, el primer mandato de Santos prioriza las relaciones internacionales del país como eje central para el desarrollo del país. En ese sentido, dentro del Plan Nacional de Desarrollo (PND) 2010-2014, Prosperidad para todos, se señalan, entre otros, como objetivos de la política exterior "fortalecer y diversificar la cooperación internacional" (Departamento Nacional de Planeación [DNP], 2010, p. 687) y, en este sentido, continúa indicando el PND, se busca direccionar la CID del país en materia de seguridad, derechos humanos y gobernabilidad democrática. Asimismo, afirma que, 
a través de la cooperación técnica[,] se fortalecerán los procesos de acercamiento a regiones de interés para el país, privilegiando la relación con países de América Latina y el Caribe. En consecuencia, se dará continuidad a las estrategias regionales de CSS de Colombia con los países de la cuenca del Caribe y Mesoamérica y se diseñarán estrategias para África y la región de Asia Pacífico. De igual manera se hará uso de la cooperación triangular por regiones. (DNP, 2010, p. 688)

Ahora bien, así como se ha señalado la diversificación temática de los temas en materia de CID, lo mismo se ha intentado hacer frente al fortalecimiento de alianzas con otros países en desarrollo en regiones más apartadas, al deiseñar para cada una diversas estrategias de acercamiento con la identificación de intereses comunes, como es el caso de la estrategia con el sudeste asiático, con Eurasia y África. Frente a la estrategia con África, por ejemplo, se han realizado visitas oficiales para gestionar proyectos de CSS. Según el Informe de gestión 2016 presentado por APC-Colombia, diversas iniciativas en materia de CSS llegaron a nueve países africanos (cancillería, s. f.).

Para el caso de Colombia, es preciso señalar que, gracias al dinámico papel que sobre política exterior ha venido desempeñando durante los últimos diez años, ha logrado paulatinamente posicionarse a nivel regional, y logrado, incluso, que sus propuestas alrededor de una gobernanza global para el desarrollo en materia social estén empezando a tener mayor acogida en foros y encuentros internacionales, como sucedió en el caso de los ODS (Suraski, 2017).

Para el cumplimiento de ambos intereses, la CSS se convierte en un instrumento privilegiado de política exterior (APC-Colombia, 2012b) a fin de alcanzar un mayor liderazgo en los debates sobre el tema (Sanín, 2010, p. 103). En 2010, por ejemplo, el país ejerció la Secretaría del Grupo de Trabajo en Cooperación Sur-Sur (TT-SSC ‘Task Team on South-South Cooperation') creado en el marco de la OCDE (por iniciativa de Colombia) y como resultado coordinó la publicación de un informe que destaca 110 estudios de casos de CSS (OECD, 2010), pero estos esfuerzos se perdieron por la falta de continuidad.

No obstante, el peso y la importancia que en el discurso se le ha dado al tema, Colombia no ha adoptado una política pública clara para el manejo de la CID, lo que se ha hecho ha sido más bien el resultado de políticas coyunturales y de Gobierno, las cuales se han insertado como objetivos o metas transversales en materia de política exterior. Estas estrategias han quedado evidenciadas dentro de los planes nacionales de desarrollo de los últimos tres periodos presidenciales, ${ }^{20}$ dentro de los cuales se señala que se busca mejorar el posicionamiento del país, principalmente en la subregión (el caso de los países centroamericanos) con los que principalmente desarrolla la CSS.

En parte, este supuesto permitiría comprender por qué para Colombia reconocer el papel que las organizaciones internacionales desempeñan como facilitadores de la construcción 
global de las políticas de desarrollo es tan importante, hasta el punto de ser uno de los países de la región más activos e, incluso, casi uno de los pocos que en cierta forma les sigue rindiendo cuentas a estos, contrario a lo que ocurre con otros de la región como Brasil.

Colombia, por su parte, busca mejorar su posicionamiento a nivel regional proclive a la defensa de los intereses nacionales de seguridad hemisférica. Su rol como receptor tradicional enmarcado en un discurso de cooperación para la paz lo ha hecho durante décadas un receptor privilegiado de la AOD tanto bilateral como multilateral.

Finalmente, cabe resaltar que el país es un agente relativamente nuevo como oferente de CID, cuya principal oferta en materia de CSS se da alrededor de los temas seguridad, esto muestra en su implementación que la cooperación técnica es una modalidad relevante para la gestión de la CSS en el país. Por lo cual, y tal como se mencionó, al país aún le queda un largo camino por recorrer frente a la ambición de ingresar como miembro en plenos poderes a la organización para la cooperación más importante y cuyos lineamientos han coordinado las políticas de CID por más de cincuenta años.

\section{Conclusiones}

En primera instancia, se planteó como punto de partida el debate alrededor de ¿Cómo hacer más eficaz la cooperación al desarrollo?, pregunta que ha estado en el centro de las reflexiones tanto políticas como académicas. En esa línea, se señalaron algunos esfuerzos que desde las organizaciones internacionales se han liderado con miras a realizar profundas reformas en el sistema internacional de cooperación al desarrollo; no obstante, es un debate inconcluso y fracturado entre posiciones ideológicas y jerárquicas que continúa predominando dentro de la CID.

Posteriormente, como parte del análisis, se hizo una descripción sobre la evolución histórica y conceptual de la CSS con el objetivo de determinar el rol de Suramérica en el proceso de consolidación de esta modalidad, de la cual se señaló surge como una propuesta complementaria a la tradicional cooperación Norte-Sur. La reflexión se ubicó inicialmente en América Latina donde se reconoce que la región ha "llegado a un nivel de madurez capaz de permitirle proponer y gestionar su propio cambio y construir su propia agenda" (Bárcena, 2015, p. 115).

No obstante, también se señaló que la CSS es un instrumento que sirve a los intereses de los países del Sur global y que, por tanto, la manera en que los Estados la ejecutan es distinta, razón por la cual se quiso analizar los casos de la CSS brasileña y colombiana, dos casos que se analizaron a partir de la definición de dos factores: la identidad, concepto propio de la teoría constructivista, y de la expertise institucional. Desde estos casos se mostró el comportamiento de cada país dentro del sistema internacional de cooperación al desarrollo en el marco de la CSS, la cual se definió y entendió como un instrumento de política exterior de estos países. 
El interés por analizar la CSS de Colombia y de Brasil es porque resultan ser interesantes exponentes de las diferencias políticas e ideologías que caracterizan al heterogéneo y diverso grupo de países que ejecutan la CSS en Suramérica. Prácticas que, además, evidencian que la "CID ha sufrido y seguirá sufriendo constantes cambios ligados a las relaciones de poder de los actores dentro de las relaciones internacionales" (Ruiz, 2017, p. 181). Asimismo, estos casos permiten analizar cómo a través de su expertise institucional se han ido insertando en distintos escenarios, dinamizando sus agendas políticas y alcanzando distintos roles, tanto a nivel global como regional, a través de la transferencia de conocimientos, experiencias y políticas internas.

Dentro del periodo analizado (2005-2015), tanto Brasil como Colombia, han pasado por cuatro administraciones, las cuales han favorecido la continuidad de sus principales objetivos de política exterior, como destacar la importancia de la cooperación internacional para mejorar (en el caso de Colombia) y de fortalecer (en el caso de Brasil) su posicionamiento internacional, así como reconocer su relevancia para mejorar el desarrollo de los países del Sur global respecto del Norte.

Este análisis demuestra, principalmente, que dentro de la CSS las potencias intermedias emergentes o regionales no son las únicas con las capacidades materiales para liderar o gestionar este proceso, sino que también las llamadas potencias secundarias pueden gestionar su CSS de manera dinámica. Con la CSS, los países pretenden posicionarse a nivel regional y tener un mayor reconocimiento internacional por los esfuerzos que realizan para gestionar de manera autónoma, y acorde con sus necesidades, sus políticas de desarrollo contando con la experiencia y el conocimiento propio y de sus socios.

Inicialmente, se planteó como objetivo analizar la CSS, tanto de Brasil como de Colombia, como herramienta de política exterior a través de dos factores: la identidad y la expertise institucional, que han promovido a lo largo de la última década las estrategias en materia de CSS de estos países.

Como ya se mencionó, desde el inicio se ha venido planteando la CSS como un instrumento de política exterior, un instrumento que utilizan los Estados del sur con el fin de alcanzar sus intereses, lo cual se evidencia en los discursos políticos que han permitido construir la identidad de cada uno en materia de CSS. Frente a esto último, lo que buscó demostrarse fue el contraste entre una visión y la otra, pues sus políticas naturalmente divergen de acuerdo con la posición que ocupan en el sistema.

"Las administraciones de Cardoso, Lula y Rousseff han orientado, en las últimas dos décadas la política exterior para proyectar y posicionar a Brasil como un jugador global y un líder regional” (Pastrana y Vera, 2012, p. 151), lo que evidencia una primacía en los temas alrededor del desarrollo y del multilateralismo, enmarcada en una "política exterior autónoma" (Flemes, 2012b, p. 26). 
Colombia, por su parte, sigue utilizando su expertise institucional en materia de seguridad, de lucha contra el terrorismo y contra el narcotráfico, y aunque ha buscado diversificar su agenda, sus principales recursos siguen proviniendo de los Estados Unidos para temas ligados con la consolidación de la paz, por lo cual ha buscado fortalecer otro tipo de modalidades como la cooperación triangular (Bergamashi, Durán, Tickner, 2017). De ahí que la triangulación ejecutada por Colombia sea descrita como de "cooperación dependiente asociada" (Tickner y Morales, 2015, p. 171).

El factor identidad se ha ido transformando acorde con las dinámicas del sistema internacional de cooperación al desarrollo; tanto Brasil como Colombia ejercen su identidad de donantes a través de su rol de receptor, pero, al mismo tiempo, quieren mostrarse ampliamente activos frente a la cooperación técnica o financiera que otorgan. Es decir que ambos actúan como donante/receptor, dualidad autoimpuesta que ha venido posicionándolos en su campo de expertise.

En cuanto a Colombia, adopta, por un lado, un comportamiento cooperativo de receptor pasivo y estable, que, incluso, no pretende modificar ni a corto ni a mediano plazo. La AOD recibida hasta el momento por el país se ha consolidado como un importante mecanismo para financiar los acuerdos de paz y de manera transversal para mejorar el desarrollo del país con miras a ingresar a la OCDE, de ahí su interés por alinearse con los compromisos establecidos desde esta organización y desde sus principales donantes como los Estados Unidos y la Unión Europea. Colombia se adhirió a la Declaración de París aceptando la condición del monitoreo, lo que demuestra que “Colombia es más proclive a una articulación con los propósitos definidos en la Declaración de París que a un involucramiento en las discusiones sobre la cooperación horizontal" (Hirst, 2011, p. 591).

Brasil, por su lado, es más propenso a buscar mecanismos alternativos de desarrollo, donde prime una visión del sur, de ahí su rechazo a los principios de la Declaración de París y su insistencia por fortalecer mecanismos interregionales. Esto último responde a una estrategia de inserción global que le permita tener un mayor peso en la toma de decisiones en las negociaciones internacionales dentro de la Organización Mundial del Comercio (OMC) como alrededor de la liberalización del comercio.

Brasil es más crítico frente a la OCDE, cuestiona más sus prácticas y políticas. En cuanto a la Declaración de París señaló que "la CSS es un acto soberano de solidaridad y ante lo cual la Declaración ha expresado su falta de idoneidad” (Hirst, 2011, p. 118). Razón por la cual el Gobierno de Brasil busca robustecer su cooperación técnica; no obstante, algunos autores señalan que para lograrlo es de vital importancia que logre “consolidar una política pública de cooperación internacional y encontrar un modelo, todavía en construcción, que diferencie a esta potencia emergente de la tradicional cooperación Norte-Sur” (Ayllón et al., 2010, p. 1). 
No obstante, según Sanahuja, es "evidente que el desarrollo del sur depende en [mayor] medida de variables como el acceso a los mercados y la tecnología, el alivio a la deuda, las políticas internas y en particular el llamado buen gobierno" (2010, p. 55) en los países en desarrollo. Para que la cooperación se materialice como un instrumento a través del cual se faciliten procesos económicos y, al mismo tiempo, se fortalezcan lazos políticos y culturales, es preciso fortalecer las instituciones nacionales a fin de poder superar los enormes retos que tanto al nivel social como económico afrontan ambos países.

La expertise institucional se ha convertido en un factor definitorio de la gestión e implementación de la CSS de los países latinoamericanos, por tanto, la reflexión anterior va encaminada a señalar la necesidad de fortalecer la institucionalidad en ambos países. Lo que en últimas los economistas Acemoglu y Robinson (2013) denominan contar con instituciones inclusivas, instituciones que fomenten la actividad económica, es decir, mercados inclusivos, con gobiernos capaces de invertir en el ámbito social, que mejoren la cobertura y el acceso a servicios públicos de calidad que permitan disminuir las marcadas brechas sociales existentes en ambos países, evidentemente entre diversas acciones en diversos campos de acción.

Se puede señalar que Brasil debe continuar profesionalizando y fortaleciendo el servicio de agentes encargados de la CID para que haya continuidad en las agendas de cooperación, lo que finalmente ha logrado gracias a esa relativa continuidad en las orientaciones de la agenda internacional que desde Itamaraty se ha alcanzado (Soares, 2005) sin mayor influencia de parte del Ejecutivo, lo que ha permitido que el país suramericano alcance un estatus de global player.

La CSS se ha caracterizado por ser netamente estatal, es decir que es gestionada, principalmente, por los Estados, a pesar del interés de los gobiernos por vincular a otros actores o, al menos, en el discurso, estos han estado ajenos a muchos procesos de formulación y ejecución, ante lo que podría señalarse que han sido invisibilizados en gran medida.

Ese carácter estatal es lo que en últimas ha permitido la identificación de cada actor en el sistema internacional de cooperación al desarrollo, ligado a lo que se mencionó del grado de expertise de cada actor frente a unos temas específicos; en el caso de Brasil se mencionaron los PTC y en el de Colombia su agenda de seguridad. Brasil ha gestionado políticas desarrollistas que en su momento resultaron exitosas en su territorio, lo que le permitió ser un referente en la materia, pero que cabe mencionar corre el riesgo de retroceder dada la actual coyuntura política y social por la que atraviesa el país.

Colombia, por su parte, se enfrenta ante el hecho de ofertar su expertise en temas que aún no han sido superados internamente como la lucha contra las drogas (la erradicación de cultivos ilícitos y seguridad ciudadana) (Marín, 2017). Ante lo cual se puede concluir que los retos a los que se enfrenta cada actor para definir su posicionamiento dependerá en mayor medida de una mayor coherencia interna. 


\section{Referencias}

Agência Brasileira de Cooperação (s. f.). Conceito. Recuperado de http://www.abc.gov. br/CooperacaoTecnica/Conceito

Agencia Presidencial de Cooperación Internacional de Colombia (2012a). Estrategia nacional de cooperación internacional 2012-2014. Recuperado de http://www20. iadb.org/intal/catalogo/PE/2013/11768es.pdf

Agencia Presidencial de Cooperación Internacional de Colombia (2012b). Manual de formulación de proyectos de cooperación internacional. Recuperado de http:// www.mincit.gov.co/loader.php?lServicio=Documentos\&lFuncion=verPdf\&id=7 6858\&name=Manual_de_Formulacion_de_Proyectos_de_CI.pdf\&prefijo=file

Agência Brasileira de Cooperação (2014). Colômbia. Recuperado de http://www.abc. gov.br/Projetos/CooperacaoSulSul/Colombia

Agencia Presidencial de Cooperación Internacional de Colombia (2015). Hoja de ruta de la cooperación internacional en Colombia 2015-2018. Recuperado de http:// ccong.org.co/files/555_at_Hoja \%20de \%20Ruta \%20de \%20la \%20Cooperaci \%C3 \%B3n \%20Internacional- \%20APC.pdf

Agencia Presidencial de Cooperación Internacional de Colombia (2016a). Informe de gestión 2016. Recuperado de https://www.apccolombia.gov.co/publicaciones/ informe-de-gestion-2016

Agencia Presidencial de Cooperación Internacional de Colombia (2016b). Marco Estratégico de Cooperación Triangular. Recuperado de https://www.apccolombia. gov.co/sites/default/files/archivos_usuario/publicaciones/marco_estrategico_de_cooperacion_triangular_de_apc-colombia.pdf

Acemoglu, D. y Robinson, J. (2013). Por qué fracasan los países: los orígenes el poder, la prosperidad y la pobreza. Bacerolan: Ariel.

Adler, E. (2013). Constructivism in international relations: Sources, contributions, and debates. En W. Carlsnaes, T. Risse y B. Simmons (eds.), Handbook of international relations (2. ${ }^{\mathrm{a}}$ ed., pp. 112-144). Los Ángeles: Sage.

Alianza del Pacífico (2015). ¿Qué es la alianza? Recuperado de https://alianzapacifico. net/que- es-la-alianza/

Altinbaş, D. (2013). South-South Cooperation: A counter-hegemonic movement? En J. Dargin (ed.), The rise of the Global South: Philosophical, geopolitical and economic trends of the 21st century (pp. 29-65). Singapore: World Scientific. 
Anheier, H. y Juergensmeyer, M. (2012). Global South. En Encyclopedia of Global Studies (pp. 725-728). Thousand Oaks: Sage.

Ardila, M., Cardona, D. y Tickner, A. (2002). Prioridades y desafíos de la política exterior colombiana. Bogotá: Hans Seidel Stiftung.

Ayllón Pino, B. (2007). La cooperación internacional para el desarrollo: fundamentos y justificaciones en la perspectiva de la teoría de las relaciones internacionales. Carta Internacional, 2(2), 32-47.

Ayllón Pino, B. (2010). La cooperación de Brasil: un modelo en construcción para una potencia emergente. Real Instituo Elcano. Recuperado de http://www.cedep. ifch.ufrgs.br/elcano.pdf

Ayllón Pino, B. (2013). La cooperación Sur-Sur y triangular: ¿̇subversión o adaptación de la cooperación internacional? Quito: Instituto de Altos Estudios Nacionales.

Ayllón Pino, B. (2017). Latinoamérica en la cooperación internacional para el desarrollo: de la subordinación a los donantes a la autonomía de la cooperación Sur-Sur. En B. Ayllón Pino y J.Á. Sotillo Lorenzo (coords.), Las transformaciones de América Latina: cambios políticos, socioeconómicos y protagonismo internacional (pp. 175-205). Madrid: Catarata.

Ayllón Pino, B. y Costa Leite, I. (2010). La cooperación Sur-Sur de Brasil. En B. Ayllón Pino et al. (coords.), La cooperación Sur-Sur en Latinoamérica: utopía y realidad (pp. 69-101). Madrid: Catarata.

Ayllón Pino, B. et al. (coords.) (2010). La cooperación Sur-Sur en Latinoamérica: utopía y realidad. Madrid: Catarata.

Ayllón Pino, B. et al. (coords.) (2013). La cooperación Sur-Sur y triangular en América Latina: políticas afirmativas y prácticas transformadoras. Madrid: Catarata.

Barcená Ibarra, A. (2015). La descolonización de la agenda para el desarrollo después de 2015: hacia una asociación universal para el desarrollo. En J. A. Ocampo (ed.), Gobernanza global y desarrollo: nuevos desafios y prioridades de la cooperación internacional (pp. 114- 157). Buenos Aires: Siglo XXI.

Bergamashi, I., Phoebe, M. y Tickner, A. (eds.) (2017). South-South Cooperation Beyond the Myts. Rising donors, New aid practices? Londres: Palgrave Mmacmillan.

Borda, S. et al. (2011). Resumen ejecutivo: informe final. En S. Borda (comps.), Misión de política exterior 2009-2010 (pp. 9-173). Bogotá: Universidad de los Andes.

Boni Aristizábal, A. (2010). El sistema de la cooperación internacional al desarrollo: evolución histórica y retos actuales. En C. Calabuig Tormo y M. de los L. 
Gómez-Torres (coords.), La cooperación internacional para el desarrollo (1. ${ }^{\mathrm{a}}$ ed., pp. 7-52). Valencia: Universitat Politécnica de Valéncia.

BrígidoBezerra,J.(ed.)(2016).Cooperação Brasileiraparao DesenvolvimentoInternacional: 2011-2013. Brasília: Instituto de Pesquisa Econômica Aplicada. Recuperado dehttp:// www.ipea.gov.br/portal/index.php?option=com_content\&view=article\&id=28542

Cancillería (s. f.). Proyecto Mesoamérica . Recuperado de http://www.cancilleria.gov. co/international/consensus/mesoamerica

Cardona, D. y Tokatlian, J. G. (1991). Los desafíos de la política internacional colombiana en los noventa. Colombia Internacional, 14, 1-8.

Cobb, R., Ross, J. K. y Ross, M. H. (1976). Agenda building as a comparative political process. American Political Science Review, 7o(1), 126-138. https://doi. org/10.1017/Sooo3055400264034

Constitución de la República Federativa del Brasil (1988). Recuperado de http://www. ilo.org/dyn/natlex/natlex4.detail?p_lang=en\&p_isn=6804

Decreto 4152/2011, 3 de noviembre, por el cual se escinden unas funciones de la Agencia Presidencial para la Acción Social y la Cooperación internacional, Acción Social y se crea la Agencia Presidencial de Cooperación Internacional de Colombia, APC-Colombia.

Departamento Nacional de Planeación (2010). Plan Nacional de 201O-2014. Recuperado de https://www.dnp.gov.co/Plan-Nacional-de-Desarrollo/PND-2010-2014/ Paginas/Plan-Nacional-De-2010-2014.aspx

Desiderá, W. A. (2015). O Brasil, a América do Sul e a Cooperação Sul-Sul. En H. Ramanzini Jr. y L. F. Ayerbe (ed.), Política Externa Brasileira, Cooperação SulSul e negociações internacionais (pp. 211-249). São Paulo: Cultura Acadêmica.

Flemes, D. (2012a). Actores estatales y regionalismo estratégico: Brasil y Colombia en el orden multipolar. En E. Pastrana Buelvas, S. Jost y D. Flemes (eds.), Colombia y Brasil: ¿socios estratégicos en la construcción de Suramérica? (pp. 25-48). Bogotá: Pontificia Universidad Javeriana.

Flemes, D. (2012b). La política exterior colombiana desde la perspectiva del realismo neoclásico. En S. Jost (ed.), Colombia: ċuna potencia en desarrollo? Escenarios y desafíos para su política exterior (pp. 19-37). Bogotá: Konrad Adenauer Stiftung.

Galán Gómez, M. y Sanahuja, J. A. (1999). El sistema internacional de cooperación al desarrollo: una aproximación a sus actores e instrumentos. Madrid: CIDEAL. 
Gratius, S. (2007, abril 1). Brasil en las Américas: ¿una potencia regional pacificadora? Recuperado de http://fride.org/publicacion/223/brasil-en-las -americas-una-potencia-regional- pacificadora

Giacalone, R. (2013). La cooperación Sur-Sur de los poderes regionales: el caso de Brasil. Mural Internacional, 4(2), 26-35.

Hirst, M. (2010). América Latina y la cooperación Sur-Sur. En B. Ayllón Pino et al. (coords.), La cooperación Sur-Sur en Latinoamérica: utopía y realidad (pp. 17-39). Madrid: Catarata.

Hirst, M. (2011). Cooperación internacional: los países de renta media latinoamericanos y la inserción de Colombia. En S. Borda et al. (eds.), Misión de política exterior 2009-2010 (pp. 553-595). Bogotá: Universidad de los Andes.

Hurrell, A. (2000). Some reflections on the role of intermediate powers in international institutions. Paths to Power: Foreign Policy Strategies of Intermediate States, 244, 1-11.

Ibáñez, J. (2015). Socialconstructivismo: ideas, valores y normas en la política mundial. En C. del Arenal y J. A. Sanahuja (coords.), Teorías de relaciones internacionales (pp. 189-218). Madrid: Tecnos.

India-Brazil-South Africa Dialogue Forum (s. f.). About IBSA background. Recuperado de http://www.ibsa-trilateral.org/about-ibsa2

Jiménez González, C. G. (2003). Las teorías de la cooperación internacional dentro de las relaciones internacionales. POLIS: investigación y análisis sociopolítico y psicosocial, 2(3), 115-147. Recuperado de http://www.redalyc.org/ pdf/726/72620305.pdf

John de Sousa, S.-L. (2007). La India, el Brasil y Sudáfrica: ¿potencias emergentes o países en desarrollo? Debate Político, Revista Iberoamericana de Anaálisis Político, 6/7, 36-48. Recuperado de http://fride.org/descarga/ART_IBSAEmerg_ESP_octo7.pdf.pdf

Jordaan, E. (2003). The concept of a middle power in international relations: Distinguishing between emerging and traditional middle powers. Politikon, 3O(1), 165-181. https://doi.org/10.1080/0258934032000147282

Lechini, G. (2007). IBSA: una opción de cooperación Sur-Sur. En A. Girón y E. Correa (coords.), Del Sur hacia el Norte: economía política del orden económico internacional emergente (pp. 271-285). Buenos Aires: Consejo Latinoamericano de Ciencias Sociales. 
Malacalza, B. (2014). La política de cooperación al desarrollo como dimensión de la política exterior desde la teoría de las relaciones internacionales. Mural Internacional, 5(2), 163-176. http://dx.doi.org/10.12957/rmi.2014.10771

Malamud, A. (2011). A leader without followers? The growing divergence between the regional and global performance of Brazilian foreign policy. Latin American Politics and Society, 53(3), 1-24.

Marín Aranguren, E. M. (2017). El 3.o de las organizaciones de la sociedad civil colombianas. En E. M. Marín Aranguren y P. X. Ruiz Camacho (eds.), Cooperación y academia: una relación pendiente en Colombia (pp. 219-268). Bogotá: Universidad Externado de Colombia.

Mignolo, W. D. (2011). The global South and world dis/order. Journal of Anthropological Research, 67(2), 165-188. https://doi.org/10.3998/jar.0521004.0067.202

Milani, C. R. y Pinheiro, L. (2017). The politics of brazilian foreign policy and its analytical challenges. Foreign Policy Analysis, 13(2), 278-296.

Naciones Unidas (1978). Conferencia de las Naciones Unidas sobre Cooperación Técnica entre los Países en Desarrollo. Recuperado de http://www.un.org/es/ documents/ag/res/33/ares33.htm

Naciones Unidas Conferencia Internacional sobre la Financiación para el Desarrollo Monterrey (México) 18 a 22 de marzo de 2002. Recuperado de http://www. un.org/es/conf/ffd/2002/pdf/ACONF1983.pdf

Nolte, D. (2006). Potencias regionales en la política internacional: conceptos y enfoques de análisis. GIGA working papers, 30. Recuperado de https://www.econstor. $\mathrm{eu} / \mathrm{handle} / 10419 / 47835$

Ocampo, J. A. (2015). Gobernanza global y desarrollo: nuevos desafíos y prioridades de la cooperación internacional. Buenos Aires: Siglo XXI.

Ojeda Medina, T. (2016). Relaciones internacionales y cooperación con enfoque SurSur. Madrid: Catarata.

Onuf, N. (1989). World of our making: Rules and rule in social theory and international relations. Nueva York: University of South Carolina Press.

Onuf, N. (1998). Constructivism: A user’s Manual. En V. Kubálhová, N. Onuf y P. Kowert (eds.), International relations in a constructed world (pp. 58-78). Londres: Routledge.

Organisation for Economic Co-operation and Development (2005/2008). The Paris Declaration on Aid Effectiveness and the Accra Agenda for Action 2005/2008. 
Recuperado de http://www.oecd.org/dac/effectiveness/parisdeclarationandaccraagendaforaction.ht $\mathrm{m}$

Organisation for Economic Co-operation and Development (2010). La cooperación SurSur en el contexto de la eficacia de la ayuda: 110 historias de caso de socios en cooperación Sur-Sur y triangular. Recuperado de http://www.oecd.org/dac/ effectiveness/46080702.pdf

Organisation for Economic Co-operation and Development (2014). Adhesión al Comité de Ayuda al Desarrollo. Recuperado de http://www.oecd.org/dac/dac-global-relations/SPANISH \%2O-\%2O16-01-14 \%20- \%20Joining \%20the \%20DAC\%2O(2).pdf

Organisation for Economic Co-operation and Development (2016). Development Co-operation Report 2016: The Sustainable Development Goals as Business Opportunities. http://dx.doi.org/10.1787/20747721

Palabras del presidente Juan Manuel Santos durante la presentación de la Agencia de Cooperación Internacional y posesión de Sandra Bessudo como directora [Video] (2012, enero 25). Recuperado de https://www.youtube.com/ watch?v=2cSiGovcmUA

Pastrana Buelvas, E. y Vera, D. (2012). Rasgos de la política exterior brasileña en su proceso de ascenso como potencia regional y jugador global. En E. Pastrana Buelvas, S. Jost y D. Flemes (eds.), Colombia y Brasil: ¿̇socios estratégicos en la construcción de Suramérica? (pp. 134- 184). Bogotá: Pontificia Universidad Javeriana.

Pauselli, G. (2013). Teorías de relaciones internacionales y la explicación de la ayuda externa. Revista Iberoamericana de Estudios de Desarrollo, 2(1), 72-92.

Pereira de Fonseca, L. (2008). La visión de Brasil sobre la cooperación internacional. Revista Española de Cooperación y Desarrollo, 22, 63-77.

Ramanzini Jr., H. y Ayerbe, L. F. (org) (2015). Política Externa Brasileira, Cooperação Sul-Sul e Negociações Internacionais. São Paulo: Cultura Acadêmica.

Ramanzini Jr., H., Passini, M. y Ribeiro, R. (2015). As diferentes dimensões da cooperação Sul-Sul na política externa brasileira. En H. Jr. Ramanzini y L. F. Ayerbe (eds.), Política Externa Brasileira, cooperação Sul-Sul e negociações internacionais (pp. 13-49). São Paulo: Cultura Acadêmica.

Ruiz Camacho, P. X. (2017). La instrumentalización de la cooperación internacional al desarrollo a través de la política exterior: una mirada interdisciplinar. En E. M. Marín Aranguren y P. X. Ruiz Camacho (eds.), Cooperación y academia: una relación pendiente en Colombia (pp. 153-188). Bogotá: Universidad Externado de Colombia. 
Sachs, J. (2014). La era del desarrollo sostenible: nuestro futuro está en juego; incorporemos el desarrollo sostenible a la agenda política mundial (trad. R. Vilá). Barcelona: Deusto.

Sagasti, F. y Prada, F. (2010). La nueva cara de la cooperación al desarrollo: el papel de la cooperación Sur-Sur y la responsabilidad social corporativa. Recuperado dehttp://www.franciscosagasti.com/descargas/actualidad/cccc-la-nueva-carade-la-cooperacion-al-desarrollo.pdf

Sanahuja Perales, J. A. (2001). Del interés nacional a la ciudadanía global: la ayuda al desarrollo y las transformaciones de la sociedad internacional. En J. A. Sanahuja Perales y M. Gómez Galán (coords.), La cooperación al desarrollo en un mundo en cambio: perspectivas sobre nuevos ámbitos de intervención (pp. 53-127). Madrid: CIDEAL.

Sanín Betancourt, M. C. (2010). La cooperación Sur-Sur en Colombia. En B. Ayllón Pino et al. (coords.), La cooperación Sur-Sur en Latinoamérica: utopía y realidad (pp. 103-123). Madrid: Catarata.

Santander Campos, G. (2016). Identidades e intereses en la cooperación Sur-Sur. Madrid: Catarata.

Schenoni, L. L. (2014). The Brazilian Rise and the Elusive South American Balance. Estudos internacionais: revista de relações internacionais da PUC Minas, 2(2), 215-231. https://doi.org/10.5752/P.2317-773X.2014v2n2p215-231

Secretaría General Iberoamericana (s. f.). ¿Quiénes somos? Recuperado de http://segib. org/quienes-somos/

Silva, L. I. da (2005). Política Externa Brasileira. En Discurso na abertura do Colóquio "Brasil: Ator Global" (vol. 1, pp. 150-159). París: Ministério das Relações Exteriores.

Soares de Lima, M. R. (2005). A política externa brasileira e os desafios da cooperação Sul-Sul. Revista Brasileira de Política Internacional, 48(1), 24-59.

Soares de Lima, M. R. y Hirst, M. (2006). Brazil as an intermediate state and regional power: Action, choice and responsibilities. International Affairs, 82(1), 21-40. https://doi.org/10.1111/j.1468-2346.2006.00513.x

Suraski, J. (2017). Cuidado con lo que deseas: América Latina en el umbral de la Agenda 2030. En B. Ayllón Pino y J. Á. Sotillo Lorenzo (coords.), Las transformaciones de América Latina: cambios políticos, socioeconómicos y protagonismo internacional (pp. 69-95). Madrid: Catarata.

Tassara, C. (ed.) (2015). Protección social y lucha contra la pobreza en Brasil, Colombia y Chile: ¿graduarse de los PTC o salir de la pobreza? Madrid: EUROSociAL. 
The Economist (2010, julio 15). Speak softly and carry a blank cheque. Recuperado de http://www.economist.com/node/16592455

The Group of 77 at the United Nations (s. f.). Latest Statements and Speeches. Recuperado de http://www.g77.org

Tickner, A. (2016). Exportación de la seguridad y política exterior de Colombia. Análisis, 12. Recuperado de http://library.fes.de/pdf-files/bueros/kolumbien/12773.pdf

Tickner, A. y Morales, M. (2015). Cooperación dependiente asociad: relaciones estratégicas asimétricas entre Colombia y Estados Unidos. Colombia Internacional, $85,171-205$.

Uribe Villa, P. (2011). Colomba: hitos y tendencias como nuevo donante. En G. Santander Campos (coord.), Nuevos donantes y cooperación Sur-Sur: estudios de caso (pp. 63-84). Madrid: Universidad Complutense de Madrid.

Vargas García, E. (2000). Cronologia das Relações Internacionais do Brasil. Río de Janeiro: Alfa Omega.

Vidal, G., Guillén, A. y Déniz, J. (coords.) (2010). Desarrollo y transformación: opciones para América Latina. Madrid: Fondo de Cultura Económica.

Vigevani, T. y Ramanzini, Jr. H. (2011). The impact of domestic politics and international changes on the Brazilian perception of regional integration. Latin American Politics and Society, 53(1), 125-155.

Wehner, L. E. (2015). Role expectations as foreign policy: South American secondary powers' expectations of Brazil as a regional power. Foreign Policy Analysis, 11(4), 435-455.

Wendt, A. (1992). Anarchy is what states make of it: The social construction of power politics. International Organization, 46(2), 391-425.

World Bank (s. f.). Net ODA received per capita (current US\$). Recuperado de https:// data.worldbank.org/indicator/DT.ODA.ODAT.PC.ZS 


\section{Notas}

$1 *$ Artículo de reflexión .

${ }^{2}$ Se utiliza el término sistema internacional de cooperación al desarrollo para hacer referencia a un conjunto heterogéneo de actores que crean una red de interacciones en diversos temas y giran alrededor del desarrollo, a través de diversas modalidades de tipo Norte-Sur, Sur-Sur, privada, multilateral, regional, entre otras (Galán y Sanahuja, 1999).

${ }^{3}$ El India-Brazil-South Africa Dialogue Forum (IBSA) fue creado por la India, Brasil y Sudáfrica tras la Declaración de Brasilia en 2003 con la idea de "contribuir a la construcción de la nueva arquitectura internacional" (IBSA, s. f.). ${ }^{4}$ Lo que en materia de la cooperación internacional al desarrollo (CID) se denomina apropiación. Un principio en el cual los países socios (receptores) deben ejercer mayor autoridad y autonomía sobre sus políticas de desarrollo, promoviendo la participación de otros actores (Organisation for Economic Co-operation and Development [OECD], 2005/2008).

${ }^{5}$ La Secretaría General Iberoamericana (Segib) fue constituida en 2003 por 22 países de Iberoamérica (más España y Portugal), que, entre otros objetivos, buscan "implementar y fortalecer la Cooperación Sur-Sur (CSS) en la región". Se destacan los informes de la CSS en Iberoamérica que desde 2007 hasta 2017 se han venido publicando. Todos están disponibles en línea en http://www.segib.org

${ }^{6}$ El debate sobre el desarrollo sostenible inició en 1972 en el marco de la Conferencia de las Naciones Unidas sobre el Medio Humano. En 1987, a través del Informe Brundtland, se define el desarrollo sostenible como "aquel que satisface las necesidades del presente sin comprometer la capacidad de las futuras generaciones para satisfacer las propias" (Brundtland, 1987, citado por Sachs, 2014, p. 22).

${ }^{7}$ Aunque su definición resulta bastante difusa por la naturaleza de sus recursos y la diversidad de asociaciones que de aquí se derivan, en términos generales, la cooperación triangular se entiende como el "conjunto de instrumentos que vinculan la CSS [cooperación Sur-Sur] con otros actores tales como países donantes del Norte, organismos internacionales y entidades privadas, con y sin fines de lucro, de los países desarrollados. Las posibilidades de asociación son muy diversas, por lo que el concepto es bastante difuso" (Sagasti y Prada, 2010, p. 35).

${ }^{8}$ Tanto Brasil como Colombia han liderado diversos procesos para la definición de instrumentos, mecanismos y objetivos con miras a un rediseño de la CID, en el cual se respeten los procesos de desarrollo local, que en últimas se convierten en una valiosa herramienta de conocimiento y de trabajo conjunto entre países con capacidades similares y nivel de desarrollo relativo. Dan cuenta de esta actividad diplomática los trabajos de Ayllón (2010), Ayllón y Costa (2010), Hirst (2011), Ruiz (2017), Sanín (2010), Tassara (2015) y Uribe (2011).

${ }_{9}^{9}$ Como ejemplo de esto puede mencionarse la Estrategia nacional de cooperación internacional 2012-2014 (Agencia Presidencial de Cooperación Internacional de Colombia [APC-Colombia], 2012a).

${ }^{10}$ Angola, Cabo Verde, Guinea-Bissau, Guinea Ecuatorial, Mozambique y Santo Tomé y Príncipe.

${ }^{11}$ A través del Proyecto Mesoamérica ha desarrollado diversos proyectos de CSS. Este proyecto es "un espacio de carácter estratégico para la integración [...], con miras a estrechar sus vínculos a partir de una agenda diversificada en la que, además de la profundización del diálogo bilateral, se fortalezca la cooperación técnica" (Cancillería, s. f.).

${ }^{12}$ América Latina, por ejemplo, es una región conformada, principalmente, por PRM. Según la lista de destinatarios de ayuda oficial al desarrollo del Comité de Ayuda al Desarrollo, 13 de los 22 países latinoamericanos entran en esta categoría en el periodo de 2014 a 2017, por tener un total de producto nacional bruto (PNB) per capita entre COP 4126 y COP 12745 a 2013 (OCDE, 2014).

${ }^{13}$ Las traducciones son mías.

${ }^{14}$ El Comité de Ayuda al Desarrollo hace parte de la Organización para la Cooperación y el Desarrollo Económico, y es el encargado de "promover la cooperación para el desarrollo, así como otras políticas que contribuyan al desarrollo sostenible a nivel internacional" (OCDE, 2014).

${ }^{15}$ Esta perspectiva se acerca al análisis neoliberal, en el que se busca darles fuerza a las instituciones. Reconoce la importancia de la interacción entre Estados, así como la acción de los organismos internacionales para darles respuesta a los problemas globales (Malalcalza, 2014).

${ }^{16}$ La resolución A/RES/64/222 de la Asamblea General de las Naciones Unidas, a través de la cual se adopta la Conferencia de Nairobi de 2009, señala estos principios en su numeral 11.

${ }^{17}$ El Plan Brasil sin Miseria (2011) fue le programa en el que el país "avanzó de forma contundente en la superación de la pobreza extrema" (Tassara, 2015, p. 29). Este programa fue uno de los proyectos bandera en materia de cooperación técnica y desarrollo ejecutados por Brasil en Sudáfrica, China, Colombia, Chile y Perú. ${ }^{18}$ La Alianza para el Pacífico, "mecanismo de integración regional conformado por Chile, Colombia, México y Perú $[. .$.$] , busca crear mercados atractivos entre sus países miembros para lograr mayor competitividad a nivel$ internacional" (Alianza del Pacífico, 2015). 


\section{Paula Ximena Ruiz Camacho}

${ }^{19}$ Estrategia presentada el 3 de agosto de 2015 (APC-Colombia, 2015).

${ }^{20}$ Bajo el mandato del presidente Álvaro Uribe Vélez, Hacia un Estado comunitario (2002-2006) y Estado comunitario: desarrollo para todos (2006-2010). Bajo el mandato de Juan Manuel Santos Prosperidad para todos (2010-2014) y Todos por un nuevo país (2014-2018). 